\title{
Rutas de Resiliencia en Italia y España. Relanzamiento y reutilización de ferrocarriles en territorios frágiles
}

Chiara Ravagnan ${ }^{1}$ | Chiara Amato ${ }^{2}$ | Francesca Rossi ${ }^{3}$ | José Maria De Ureña 4

Recibido: 2019-06-11 | en su versión final: 2020-12-08

Resumen

\begin{abstract}
Los procesos de metropolización del territorio impulsan fenómenos de polarización espacial que determina un estado creciente de fragilidad económica y social de las "inner peripheries" conectada a fenómenos de abandono del patrimonio edificatorio y de infraestructuras. En este contexto, el grupo de académicos italianos y españoles ha desarrollado entre 2018 y 2020 la investigación intitulada Rutas de resiliencia. Reutilización y relanzamiento de ferrocarriles menores para la regeneración de los territorios frágiles. Experiencias en Italia y España. La investigación, a partir de la contextualización de las dinámicas en Italia y España, como la marginalización de las "aree interne" y de la "España vacía", define nuevas referencias metodológicas y operativas orientadas a responder a los procesos de desmantelamiento infraestructural, en línea con las estrategias europeas. La investigación adopta tres perspectivas consolidadas en el marco del debate urbanístico para analizar los fenómenos de fragilización y las experiencias en curso y para proponer pautas de intervención: una perspectiva "estructural" para el relanzamiento del servicio ordinario, una perspectiva "morfológica y paisajística" de puesta en valor del carácter cultural y turístico de los ferrocarriles y una perspectiva "ecológica" para la construcción de vías verdes. En este marco, a partir de una metodología inductiva, el documento representa una síntesis de los resultados y algunas profundizaciones de casos de estudio que subrayan la oportunidad de experimentar nuevas categorías integradas y multiescalares para la planificación de redes de infraestructuras, promovidas por las políticas y los programas nacionales y europeos.
\end{abstract}

Palabras clave: despoblación; Infraestructuras; regeneración; sostenibilidad

Citación

Ravagnan, C. et al. (2021). Rutas de resiliencia en Italia y España. Relanzamiento y reutilización de ferrocarriles en territorios frágiles. ACE: Architecture, City and Environment, 15(45), 10369. DOI: http://dx.doi.org/10.5821/ace.15.45.10369

\section{Resilience Paths in Italy and Spain. Railways Relaunch and Reuse in Fragile Territories}

Abstract

\begin{abstract}
The processes of metropolization of the territory foster phenomena of spatial polarization that determine a growing state of economic and social fragility of the "inner peripheries" connected to the abandonment of the building and infrastructural heritage. In this context, between 2018 and 2020, the group of Italian and Spanish academics has developed the research entitled Resilience Paths. Reuse and relaunch of minor railways for the regeneration of fragile territories. Experiences in Italy and Spain. The research, based on the contextualization of the dynamics in Italy and Spain, such as the marginalization of the "aree interne" and the "España vacía", defines new methodological and operational references aimed at facing the processes of infrastructural dismantling, in line with European strategies. This research adopts three consolidated perspectives, within the framework of the urban planning debate, to analyse the fragilization phenomena. Moreover, the ongoing experiences and to propose guidelines for intervention: a "structural" perspective for the relaunch of the ordinary service, a "morphological and landscape" perspective for the enhancement of the cultural and tourist character of the railways and an "ecological" perspective for the construction of greenways. In this framework, based on an inductive methodology, the document represents a synthesis of the results and some insights into case studies that highlight the opportunity to experiment new integrated and multi-scalar categories for the planning of infrastructure networks, promoted by the national and European policies and programs.
\end{abstract}

Keywords: depopulation; infrastructures; regeneration; sustainability

${ }^{1}$ Departamento PDTA, Sapienza Università di Roma (ORCID: 0000-0002-6036-1313, Scopus Author ID: $\underline{57191847896}$, 2 Departamento PDTA, Sapienza Università di Roma (ORCID: 0000-0002-7089-5538), ${ }^{3}$ Departamento PDTA, Sapienza Università di Roma (ORCID: 0000-0003-3057-6070), ${ }^{4}$ Departamento de Ingeniería Civil y de la Edificación, Universidad Castilla-La Mancha (ORCID: 0000-0002-0404-1454, WoS ResearcherID: R-3434-2017, Scopus Author ID: 7003534722). Correo de contacto: chiara.ravagnan@uniroma1.it 


\section{Introducción. Objetivos y metodología de la investigación Rutas de resiliencia}

Los frentes más avanzados del debate sobre la regeneración sugieren la oportunidad de contrastar la marginalidad y el abandono de las "inner peripheries", poniendo en el centro de las estrategias territoriales las opciones vinculadas al fortalecimiento, la reutilización y la reactivación de las redes infraestructurales (Carta y Ronsivalle, 2015; Ravagnan et al., 2020). Estas redes se configuran como componentes estratégicos, "matrices de regeneración" capaces de contrastar el debilitamiento progresivo del "alma" de los territorios sujetos al abandono y la despoblación y de experimentar "rutas de resiliencia" a los cambios sociales, económicos y medioambientales. Recuperar a los restos de infraestructura (Figura 1) "desde fondo hasta figura" para la construcción de escenarios de regeneración es una operación compleja pero indispensable en lo que concierne a la habitabilidad y la seguridad de los territorios. Aspectos que no dependen de la calidad técnica de algunas intervenciones puntuales y sectoriales, sino de "la calidad general y la escala múltiple de las redes de relación: física, cultural, económica, social" (Di Venosa et al., 2018).

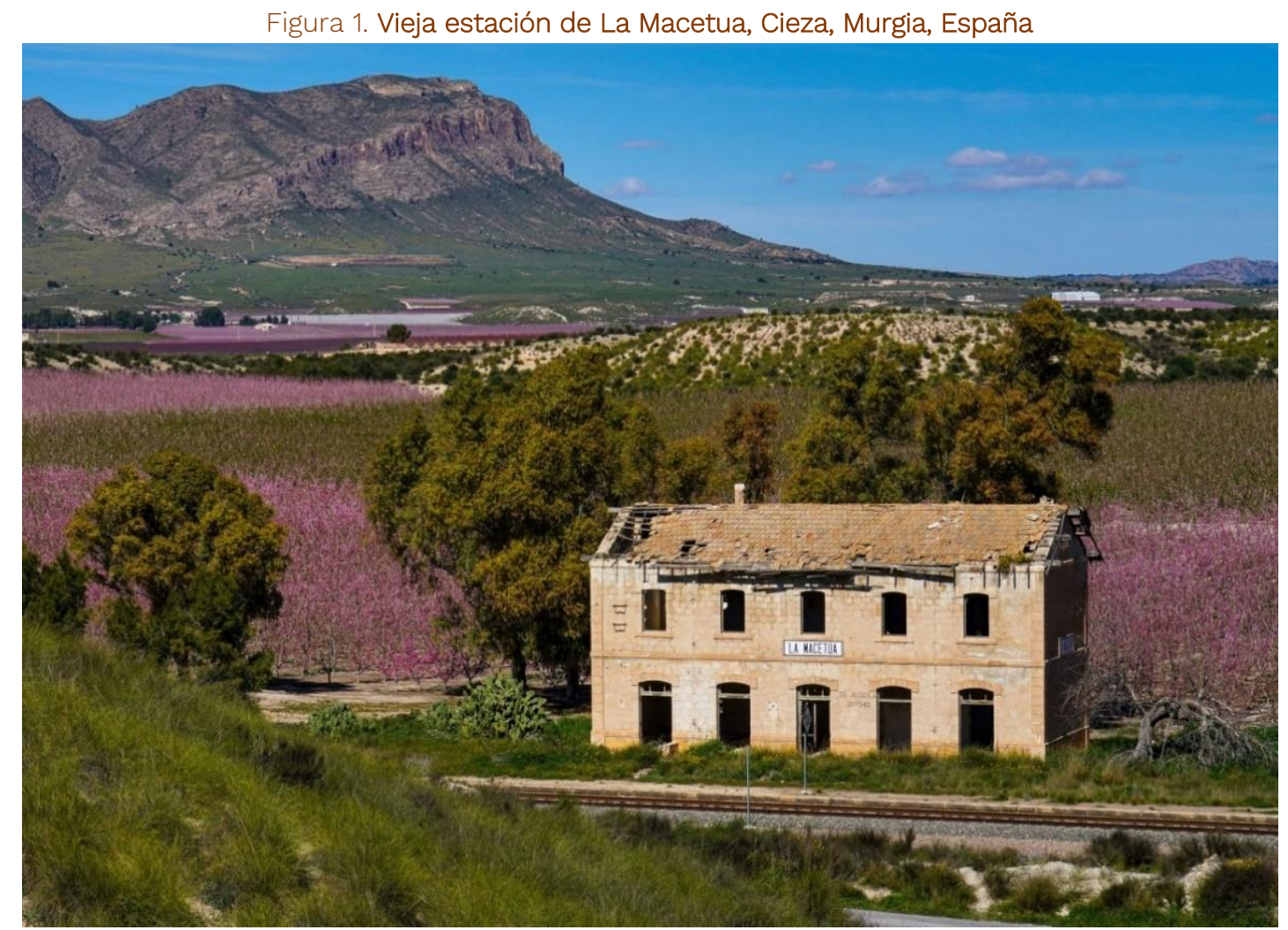

Fuente: iStock.com/Rudolf Ernst.

En este contexto, la investigación internacional "Rutas de resiliencia. La reutilización y el relanzamiento de los ferrocarriles secundarios para la regeneración de territorios frágiles. Experiencias en Italia y España" que el grupo de académicos de las Universidades Sapienza, Roma Tre, Tor Vergata (Italia) y las Universidades Castilla-La Mancha y Politècnica de Catalunya (España), ha llevado a cabo entre 2018 y 2020, persiguió el objetivo de recomponer las referencias metodológicas y operativas para el relanzamiento y la reutilización de líneas ferroviarias en el contexto de estrategias generales para la regeneración de territorios frágiles (Ravagnan, 2019; Ravagnan y Amato, 2020). Líneas de intervención, por lo tanto, en el marco de un enfoque integrado que contempla diferentes

ACE, X (XX) CC BY-ND 3.0 ES | UPC Barcelona, España | Rutas de resiliencia en Italia y Espala. Relanzamiento y reutilización de ferrocarriles en territorios frágiles. DOI: http://dx.doi.org/10.5821/ace.15.45.10369 
perspectivas disciplinares (urbanística y territorial, paisajística, social, económica, jurídica) y diferentes políticas, portadoras de nuevas categorías de proyectos, criterios operativos, formas de gestión y canales de financiación.

Este enfoque asume el concepto de "resiliencia" (Pike et al., 2010; Battisti, 2020) como referencia contra el abandono y la despoblación de "áreas internas" (Italia), "vacías" (España) y recuerda, en este sentido, el carácter proactivo del dinamismo y la adaptación a los retos de conectados a los cambios ambientales y socioculturales (Cerasoli, 2017).

En este contexto de investigación y experimentación, este trabajo pretende subrayar cómo las infraestructuras de movilidad representan un componente involucrado en el círculo vicioso que invierte a los territorios periféricos históricos en los procesos de abandono y decadencia y, al mismo tiempo, cómo constituyen la "condición” para la revitalización y regeneración de ciudades más pequeñas, respaldada por herramientas innovadoras y canales de financiación específicos. Además, la investigación intenta subrayar la importancia de las políticas nacionales e internacionales que promueven, al mismo tiempo, experiencias de cooperación intermunicipal y la innovación propuesta por prácticas de cooperación público-privada.

El paper sintetiza los resultados de la investigación, que ha adoptado una metodología inductiva e iterativa, estructurada en tres partes: una primera parte de contextualización de los fenómenos y de los enfoques relacionados a las "inner peripheries" en Italia y España; una segunda parte de profundización del debate y de las experiencias emblemáticas (políticas y programas, planes y proyectos), a través de tres perspectivas consideradas "paradigmas"; una tercera parte de propuesta de referencias teóricas, metodológicas y operativas para transformar los ferrocarriles abandonados en proyectos multiescalares de regeneración.

\section{Inner peripheries y derecho a la movilidad. Fenómenos y enfoques disciplinarios}

\subsection{Inner peripheries, aree interne y España vacía}

En los últimos años, las agendas nacionales e internacionales se han centrado en el lado más desconcertante de la "metropolización del territorio" (Font Arellano, 2007), materializándose en los fenómenos de marginación social, empobrecimiento progresivo de los ecosistemas históricos, ambientales y productivos que ayudaron a construir la riqueza y la belleza de Europa. Hoy en día, estos parecen estar debilitados por su misma "alma”, los flujos de personas y bienes que disminuyen en un círculo vicioso de desequilibrio socioeconómico, despoblación, desmantelamiento de las infraestructura y exclusión social (Pignatti et al., 2019; Ravagnan, 2019).

Como se desprende de las actividades de investigación del Programa ESPON-Profecy (AAVV, 2017), en Europa están surgiendo situaciones de polarización y congestión de los grandes centros urbanos y, al otro lado, de deterioro socioeconómico de vastas áreas geográficas conectadas a estructuras morfológicas, funcionales, demográficas específicas, a considerable distancia de las principales ciudades y centros de actividad económica y, en consecuencia, de servicios de interés general: las "inner peripheries".

La comparación de los programas nacionales de investigación de los países europeos dibuja diferentes aspectos del equilibrio territorial entre áreas costeras y áreas de montaña, áreas congestionadas y áreas abandonadas.

ACE, X (XX) CC BY-ND 3.0 ES | UPC Barcelona, España | Rutas de resiliencia en Italia y Espala. Relanzamiento y reutilización de ferrocarriles en territorios frágiles. DOI: http://dx.doi.org/10.5821/ace.15.45.10369 
Figura 2. Densidad de población datos GEOSTAT, 2011 (ab/ $\left.\mathrm{Km}^{2}\right)$ - extracto (izq.);

Evolución de la población en las shrinking rural regions, 2001-2011 (der.)

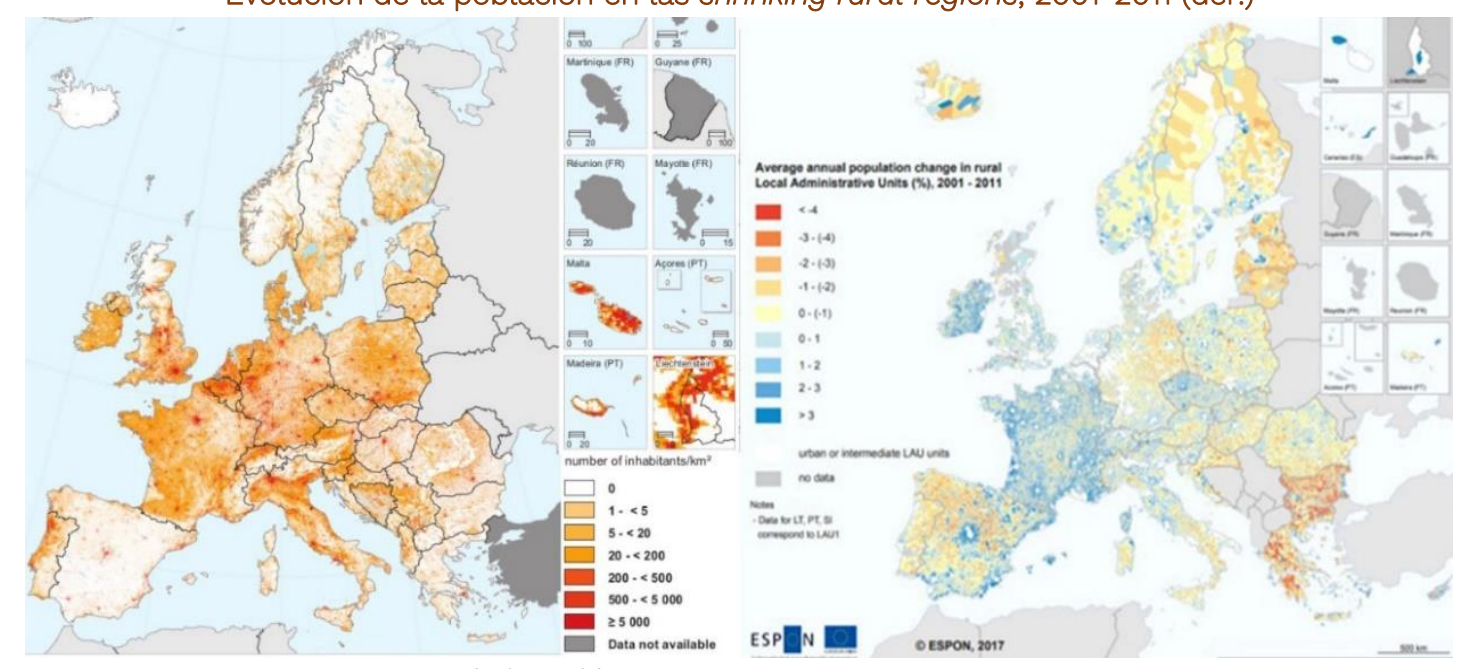

Fuente: JRC, Eurostat, Geostat Population grid, 2011; ESPON, 2018.

Los mayores desequilibrios se pueden releer precisamente en los países del "arco latino" (España, sobre todo, Italia, Francia) y de Europa occidental, así como en el norte de Europa, Suecia y Noruega (Figura 2), mientras que las brechas entre áreas altamente urbanizadas e "inner peripheries" aparecen menos marcados en los países de Europa del Este, sujetos a procesos de shrinkage internacional más amplios y a un menor desempeño de las áreas urbanas (Figura 3; ESPON, 2017, ESPON, 2018).

Figura 3. Número relativo de shrinking rural regions en los paises europeos 1961-2001

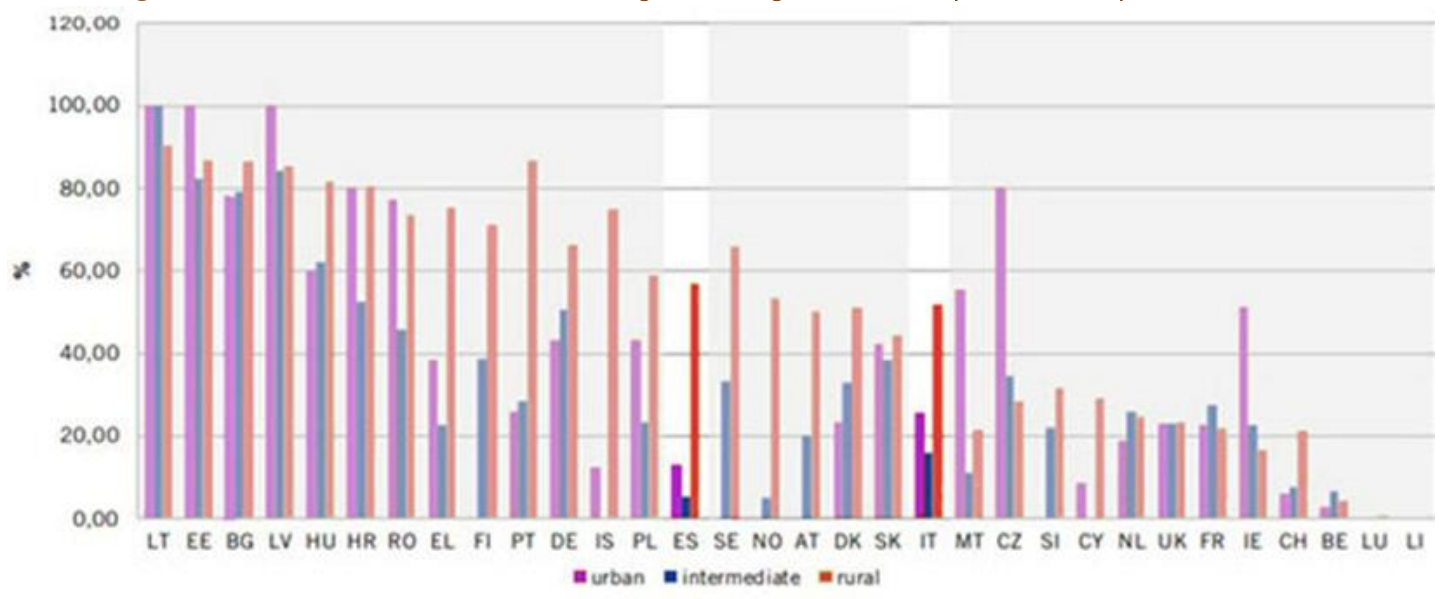

Fuente: ESPON, 2018.

La evidencia de los desequilibrios y de este "drenaje de la población" de los "enclaves" territoriales a las zonas urbanas se remonta a factores tanto intrínsecos como extrínsecos abordados en los estudios realizados en el marco del Programa ESPON-Profecy (ESPON, 2017).

Por un lado, la investigación ESPON-Profecy confirma que las principales periferias interiores se caracterizan por un "bajo potencial económico ligado a las características geomorfológicas" y escasa "conectividad" por corresponder a zonas de montaña, con alta vulnerabilidad, baja mutabilidad y escasa conexión con sistemas de infraestructura, desde los Apeninos hasta los Alpes, los Pirineos, pasando por el Massif Central hasta los Cárpatos de Europa Central y Oriental. Hoy, sin embargo, la

ACE, X (XX) CC BY-ND 3.0 ES | UPC Barcelona, España | Rutas de resiliencia en Italia y Espala. Relanzamiento y reutilización de ferrocarriles en territorios frágiles. DOI: http://dx.doi.org/10.5821/ace.15.45.10369 
periferia no solo está ligada a los aspectos geográfico-espaciales y a la distancia, como se señala en el mismo estudio. El declive económico, de hecho, a menudo se desencadena por factores socioeconómicos y demográficos relacionados con el abandono de las actividades económicas y el equipamiento, el envejecimiento de la población y la baja especialización de los trabajadores, lo que conduce a un bajo consumo y capacidad de innovación, con el aumento asociado del desempleo. En este marco, es posible delinear similitudes entre los fenómenos de las zonas de la España vacía (Del Molino, 2016; Recaño, J. 2017) y de las Aree interne italianas (Barca et al., 2014), aunque la evolución histórica sea diferente.

En la clasificación reciente de las "aree interne" italianas, iniciada en 2012 por el entonces Ministero della Coesione Territoriale, se definen como un conjunto de pequeñas ciudades, pueblos, asentamientos de montaña, con niveles variables de periferia, áreas sustancialmente distantes de los centros de suministro de servicios, y caracterizadas por los procesos de degradación, despoblación y aislamiento (Barca et al., 2014). La Strategia Nazionale per le Aree Interne (SNAI), administrada por la Agenzia per la Coesione Territoriale, tiene come objetivo el desarrollo de estas áreas a través de fondos ordinarios de las Leggi di stabilità y fondos de la UE 2014-2020 (FEDER, FSE, FEADER, FEMP) para contrarrestar el declive demográfico de las "aree interne", tomando nota de las condiciones de marginación que éstas han sufrido, y desplegando acciones para adaptar los servicios esenciales, salud, educación y movilidad, que hacen frente a las instancias de ciudadanía y los proyectos de desarrollo local, que mejoran el patrimonio natural y cultural de estas áreas. Dentro de la SNAI, el tema de la movilidad es emblemático de la complejidad con la cual abordar la intervención en las "aree interne" y del potencial económico, social y medioambiental de las intervenciones, como se desprende de las Linee guida per gli interventi sulle aree progetto que, a partir del reconocimiento del Derecho a la movilidad como un derecho de la ciudadanía, intentan responder a una necesidad de movilidad (ordinaria y turística).

Los países de la Europa occidental y mediterránea son, por tanto, los más afectados por los desequilibrios entre las zonas urbanas y rurales/montañosas, "territorios en contracción" en zonas de baja urbanización, caracterizados por diferentes formas de "periferia". En España, donde en el año 2018, el 61,5\% del total de municipios contaban con menos de 1.000 habitantes (Instituto Nacional de Estadística, 2018), la Federación Española de Municipios y Provincias (FEMP) ha afirmado en un "Documento de Acción de la Comisión de Despoblación" del año 2017 que la regresión demográfica se ha convertido en un problema nacional y como tal ha de responderse a él desde una perspectiva de gobernanza multinivel que, en la práctica, conlleva la implicación de todas las administraciones públicas en todos sus frentes de acción. En este sentido, la FEMP plantea el reequilibrio territorial y la lucha contra la despoblación como una inversión en cohesión social y territorial y en el fortalecimiento sostenible del modelo económico y social, a partir de las infraestructuras, servicios básicos y comercios.

\subsection{Territorios frágiles, derecho a la movilidad y desarrollo sostenible}

Este aislamiento es, en primer lugar, el resultado de fenómenos culturales, como el boom de la década de 1960 en el transporte por carretera y la marginación del transporte público a una visión anacrónica y no muy moderna de la movilidad (Cerasoli, 2015), y políticos, a partir de las decisiones que impulsan transporte individual, liberalización ferroviaria y construcción de la Alta Velocidad (AV) (Bellet Sanfeliu, 2013, Ravagnan et al., 2020). La AV aumenta una "geografía del poder" basada en territorios de alta y baja rentabilidad, aquellos atendidos por la red principal que refuerzan la conexión entre los núcleos más importantes y aquellos caracterizados por el efecto túnel; es decir, la falta de estaciones en los espacios intermedios (De Ureña, 2012, Menéndez et al., 2002, 2004).

Estas dinámicas han producido serios costos sociales, ecológicos, ambientales y urbanos (desigualdades sociales, consumo de suelo, contaminación del aire, fragmentación urbana,

ACE, X (XX) CC BY-ND 3.0 ES | UPC Barcelona, España | Rutas de resiliencia en Italia y Espala. Relanzamiento y reutilización de ferrocarriles en territorios frágiles. DOI: http://dx.doi.org/10.5821/ace.15.45.10369 
disminución de la calidad de vida, reducción de los lugares de relación), que hoy recuerdan la necesidad de una estrategia que se enfoque hacia el transporte público, particularmente al ferrocarril, en su característica de red capilar, de medio sostenible de movimiento y de recurso para el reequilibrio territorial, dejando la lógica puramente de transporte para considerar las grandes infraestructuras como obras territoriales (Dematteis, 2001), un capital social fijo y, por lo tanto, un lugar de recomposición entre ciudadanos y territorio.

La situación de crisis multisectorial (socio-económica y medioambiental) que está afectando a las áreas más frágiles y marginales de países como Italia y España, y, en paralelo, las políticas y programas de movilidad de ferrocarriles, sugieren la importancia de reconocer el Derecho a la movilidad como un derecho primario de ciudadanía, no solo para los suburbios de los grandes centros urbanos - en el que se concentra el debate científico - sino sobre todo para las áreas marginales. En una "sociedad líquida", globalizada, basada en conexiones y velocidad de interacción, las infraestructuras para la movilidad sostenible constituyen la armadura territorial para la resiliencia de los territorios, ejes estratégicos de revitalización, capaces de definir los caminos rápidos y lentos, y para reactivar economías, dirigir flujos y redescubrir territorios.

El recurso para hacer esto es un capital social fijo que puede definirse como "un activo sin el cual las actividades productivas primarias, secundarias y terciarias no pueden funcionar (...) lo esencial del concepto puede restringirse al transporte y la energía" (Hirschman, 1958, pàg. 97). En Italia, el patrimonio ferroviario abandonado consiste en alrededor de $7.500 \mathrm{~km}$, entre líneas en desuso y subutilizadas, mientras que en España es de unos 5.500 km (Tabla 1). Estas líneas abandonadas, con el cese del servicio han traído consigo fragmentos de territorio, fragmentos de economías, en un círculo vicioso de abandono y despoblación que es necesario revertir dando nueva vida a estas "ramas secas".

Tabla 1. Datos sobre territorios y ferrocarriles italianos y españoles

\begin{tabular}{|c|c|c|}
\hline & Italia & España \\
\hline Superficie total & $302.073 \mathrm{~km}^{2 \circ}$ & $504.645 \mathrm{~km}^{2 *}$ \\
\hline Población total & $60.376 .408 \mathrm{ab}^{\circ}$ & $47.198 .000 \mathrm{ab}^{*}$ \\
\hline Densidad total & $199,82 \mathrm{ab} / \mathrm{km}^{2}$ & $92 \mathrm{ab} / \mathrm{km}^{2 *}$ \\
\hline Sup. áreas urbanas & $121.958 \mathrm{~km}^{20}$ & $236.562 \mathrm{~km}^{2 * *}$ \\
\hline \% sup. áreas urbanas & $40 \%$ & $47 \%$ \\
\hline Población áreas urbanas & $46.153 .200 \mathrm{ab}{ }^{\circ}$ & $39.418 .215 a b^{* *}$ \\
\hline \% población áreas urbanas & $77 \%$ & $84,89 \%$ \\
\hline Sup. áreas internas & $180.115 \mathrm{~km}^{2 \circ}$ & $268.083 \mathrm{~km}^{2 * *}$ \\
\hline \% sup. áreas internas & $60 \%$ & $53 \%$ \\
\hline Población áreas internas & $13.280 .544 a b^{\circ 0}$ & $7.133 .237 \mathrm{ab}$ ** \\
\hline \% población áreas internas & $22,3 \%$ & $15,11 \%$ \\
\hline Ferrocarriles - total & $26.500 \mathrm{~km}^{\circ 00}$ & $15.301 \mathrm{~km}^{\star \star \star}$ \\
\hline Ferrocarriles abandonados (en desuso y suspendido) & $7.500 \mathrm{~km}{ }^{\infty 00}$ & $5.476 \mathrm{~km}{ }^{\star \star \star}$ \\
\hline
\end{tabular}

Fuente: Elaboración propia con datos de: ${ }^{\circ}$ ISTAT - Istat Istituto di Statistica 2019. ${ }^{\circ}$ Strategia Nazionale Aree Interne con datos ISTAT. Por áreas urbanas entendemos aquellas clasificadas como Polo, Polo intermedio y Cintura. Por áreas internas entendemos aquellas clasificadas como Intermedio, Periférico y ultraperiférico. ${ }^{\infty}$ Database Ferrovieabbandonate.it, con datos Ferrovie dello Stato Italiane. Por ferrocarriles en desuso nos referimos a líneas FS y a líneas de concesión. * Instituto Nacional de Estadistica, 2018. Para el cálculo de las áreas internas se tiene en cuenta la subdivisión de España vacía de Sergio del Molino (Regiones áreas internas: Aragón, CastillaLa Mancha, Castilla y León, Extremadura, La Rioja; Regiones áreas urbanas: Andalucía, Principado de Asturias, Illes Balears, Canarias, Cantabria, Cataluña, Comunitat Valenciana, Galicia, Comunidad de Madrid, Región de Murcia, Comunidad Foral de Navarra, País Vasco). ** Ministerio de Fomento, Gobierno de España. ***Fundación del Ferrocarril y Adif. Se entienden los ferrocarriles bajo la titularidad Adif - Administrador de Infraestructuras Ferroviarias: https://www.elmundo.es/economia/2017/09/04/59ac4ad5e2704e11478b45a4.html, 2019. 


\subsection{Perspectivas de resiliencia}

Estudios y políticas recientes sobre territorios frágiles (Pignatti et al., 2019) requieren la implementación de nuevos enfoques holísticos que conduzcan a estrategias inspiradas en objetivos comunes de desarrollo sostenible (Naciones Unidas, 2015) y al mismo tiempo que ofrezcan una estrategia para revertir el círculo vicioso existente y configurar planes y proyectos enraizados en las necesidades locales y los recursos endógenos. Planes y proyectos que por un lado estimulan de forma proactiva la dinamización económica y social para recuperar esa alma de los flujos de personas y mercancías, pero por otro ofrecen soluciones aplicables en zonas con bajos niveles demográficos, gracias a un uso integrado de redes materiales y redes intangibles - sociales, culturales, tecnológicas.

En línea con la agenda nacional y europea, la investigación de Rutas de resiliencia ha acogido la necesidad disciplinar, consolidada en los frentes avanzados del debate científico (ESPON, 2017; ESPON, 2018), de adoptar un enfoque de análisis interdisciplinario y multiescalar sobre los fenómenos en curso y la definición de estrategias de resiliencia para "territorios frágiles".

Un enfoque que parte de la conciencia de la profunda interrelación entre las diferentes formas de "fragilidad": La fragilidad social, vinculada a la contracción de los derechos de ciudadanía, la disminución de la calidad de vida de las personas y al origen de los fenómenos de despoblación; la fragilidad económica, que engendra un círculo vicioso de empobrecimiento del patrimonio público y privado; y la fragilidad ecológico-ambiental, que alimenta el abandono y determina la escasa seguridad de los contextos "sensibles".

El concepto de "resiliencia" es portador de algunas líneas de actuación compartidas a nivel europeo y cada vez más relacionadas con el tema de la fragilidad, vulnerabilidad y marginación de territorios fuera de la cuenca de los grandes núcleos urbanos (Ravagnan y Amato, 2020). En particular, en esta investigación, se entiende como la capacidad de un sistema territorial para responder a los cambios en el contexto y reorganizarse en un estado de equilibrio a través de:

- Adaptación a los cambios sociales, demográficos y al contexto económico de los pequeños municipios, en relación con la escasez de recursos, una población decreciente y un envejecimiento constante, desarrollando nuevas formas de planificación y gestión de redes materiales e intangibles conectadas a las ICT (Information and Communication Technologies), movilidad inclusiva y "on demand", con el apoyo de formas de asociación institucional y gestión asociada de servicios;

- Promoción de modelos de desarrollo y movilidad basados en especificidades territoriales y recursos endógenos (patrimonio cultural, paisaje, espacios abiertos) así como en la diversificación de soluciones de diseño en una perspectiva sólida para gestionar condiciones de incertidumbre y variabilidad de flujos estacional (Blecic y Cecchini, 2016);

- Acciones proactivas de desarrollo sostenible vinculadas a la economía circular, verde y baja en carbono mediante la experimentación con modelos de vivienda, actividades y transporte no contaminantes, potenciando los espacios para no consumir (Gasparrini, 2015) como "bienes comunes", capaces de proporcionar servicios ecosistémicos (Naciones Unidas, 2005), a través de un enfoque participativo, vinculado a acciones de difusión, sensibilización, empoderamiento.

Las políticas, planes y proyectos de regeneración territorial deben, entonces, incorporar la creciente apertura de los límites disciplinares y los campos de atención de las herramientas en la dirección de un enfoque holístico, sostenible y resiliente del desarrollo territorial que vincule infraestructuras, movilidad, territorio y medio ambiente (Cerasoli, 2012). En ese sentido, se identifica:

- Una perspectiva estructural-funcional que persigue la expansión de los derechos de ciudadanía,

ACE, X (XX) CC BY-ND 3.0 ES | UPC Barcelona, España | Rutas de resiliencia en Italia y Espala. Relanzamiento y reutilización de ferrocarriles en territorios frágiles. DOI: http://dx.doi.org/10.5821/ace.15.45.10369 
en el sentido de la problemática ambiental y la movilidad (Lefebvre, 1968; Naciones Unidas, 2015), promoviendo un reequilibrio de dotaciones infraestructurales para la escala nacional con la garantía de servicios intermodales, en apoyo al necesario relanzamiento del transporte público sostenible e inclusivo. La recuperación del servicio público es importante para contrastar los efectos que la liberalización ha tenido en el transporte ferroviario y de pérdida de la vocación pública del servicio y la distribución justa del "derecho a la movilidad" como derecho de la ciudadanía. En esta perspectiva, la investigación propone diferentes experiencias que recogen el papel fundamental del transporte público en las áreas cada vez menos accesibles y pobladas, para el mantenimiento de estilos de vida sostenibles y el acceso a lugares centrales, a los servicios básicos como educación, salud, cultura, coordinando los sistemas de trasporte público genérico con los sistemas de transporte sectoriales (sanitario, postal, educativo, etc.) para crear formas de movilidad más sostenible (Ruiz de la Riva et al., 2015).

- En esta dirección, también se configura una perspectiva histórico-morfológica, que registra el progresivo reconocimiento del valor cultural y económico de las "infraestructuras históricas" (canales, ferrocarriles, etc.), que contribuyen a la valorización de la morfología de los lugares y la identidad de las comunidades, a partir del carácter propio de las matrices de asentamiento y de "patrimonio y capital territorial" (Consejo Europeo, 2005; Naciones Unidas, 2015). Esta perspectiva se centra en la relación osmótica entre infraestructura y paisaje, a partir del reconocimiento de la forma como una herramienta cognitiva y de diseño para captar la identidad de los lugares y la fruición como elemento indispensable para gobernar la percepción del territorio. En este sentido, la dimensión paisajística de las infraestructuras ferroviarias constituye un tema emergente de reflexión que desarrolla el carácter de identidad de los "ferrocarriles turísticos", a través de líneas destinadas a la valorización del paisaje y del patrimonio abandonado (líneas, estaciones, puentes, viaductos y túneles), junto con la revitalización de los contextos territoriales (Treu y Peraboni, 2016).

- Por fin, en un tercer enfoque cobra importancia una perspectiva medioambiental, en la que la movilidad suave (Unión Europea, 2000) puede representar el hilo rojo para la inserción de los centros históricos en los itinerarios internacionales de turismo sostenible (como la red Eurovelo) y como estructura de referencia para la construcción de infraestructuras verdes, concebidas como redes de espacios abiertos planificados a nivel estratégico capaces de proporcionar servicios ecosistémicos (Comisión Europea, 2013). Una perspectiva que intenta estructurar infraestructuras verdes, trayendo nuevas conexiones entre áreas de alta naturalidad, nuevas formas de movilidad y usos ecológicos en contextos frágiles y nuevas economías circulares y verdes conectadas a valores colectivos orientados al cuidado y al respeto por el medio ambiente.

En estas perspectivas, las infraestructuras se configuran como ejes estructurantes de reequilibrio territorial, como redes de lugares de identidad, como infraestructuras integradas (gris y verdes) portadoras de nuevas formas de movilidad sostenible y nuevos valores colectivos orientados al medioambiente y a la memoria.

En coherencia con estas perspectivas, se ilustran las políticas y programas centrados en territorios frágiles y en el relanzamiento y reutilización de líneas ferroviarias. En relación con estos marcos político-legislativos, se analizan casos emblemáticos de planes y proyectos, en los que es posible destacar el papel principal atribuido al abandono de las líneas de ferrocarril en los procesos de "fragmentación" de los territorios y, al mismo tiempo, las oportunidades de regeneración derivadas de las intervenciones en infraestructuras, verdaderas "rutas de resiliencia", portadoras de nuevas economías, nuevos lugares de identidad y nuevos valores ecológicamente orientados.

ACE, X (XX) CC BY-ND 3.0 ES | UPC Barcelona, España | Rutas de resiliencia en Italia y Espala. Relanzamiento y reutilización de ferrocarriles en territorios frágiles. DOI: http://dx.doi.org/10.5821/ace.15.45.10369 


\section{Italia y España. Políticas y programas nacionales y europeos entre revitalización y reutilización de líneas ferroviarias abandonadas}

\subsection{La políticas nacionales y europeas}

En Italia y España, la presencia de las líneas ferroviarias abandonadas aparece como una oportunidad tanto para la reactivación del servicio ferroviario, a través de nuevos corredores para la movilidad ordinaria/general en ferrocarril, como para una perspectiva turística, a través del establecimiento de trenes históricos y la conversión de los trazados en vías verdes (Amato, 2018). En particular, algunas experiencias que estan profundizadas en la investigación demuestran que las Regiones pueden tomar protagonismo en la reorganización y el relanzamiento definiendo algunas líneas prioritarias para ser mantenidas como servicio público, junto con los gobiernos nacionales que pueden financiar el déficit de funcionamiento de estas líneas. De hecho, si en las áreas urbanas la reutilización de líneas ferroviarias en desuso se traduce principalmente en nuevas oportunidades para movilidad alternativa (eléctrica, autónoma, etc.), en áreas internas (vacías) el uso de estos recursos latentes puede apoyar estrategias de desarrollo local y regeneración más complejas.

El carácter interescalar de las estrategias de regeneración de los territorios frágiles y marginales en relación con la revitalización del servicio ferroviario sólo puede adoptar un enfoque multiescalar hacia una posible integración con los escenarios europeos y nacionales, aprovechando las oportunidades indispensables otorgadas por los programas de financiación. La UE representa el contexto donde se describen las grandes estrategias de planificación territorial, las prioridades de acción y los programas de financiación relevantes para los proyectos de infraestructuras. En particular, en 1992 se lanzó el proyecto TEN (Trans European Networks), que luego se actualizó con la red TEN-T definida por el Reglamento europeo 1315/2013, destinado a crear una red de transporte europea interconectada e integrada, tanto geográficamente como para sistemas de transporte, con el objetivo de garantizar la continuidad de las rutas, crear nuevas redes (ferrocarriles de alta velocidad y autopistas), adaptar las redes existentes, armonizar la tecnología y hacer que los distintos segmentos sean interoperables.

De los nueve corredores que constituyen la columna vertebral de la red TEN-T, cuatro interesan a Italia, cruzándola de norte a sur y de oeste a este, el Báltico-Adriático, el Escandinavo-Mediterráneo, el Rin-Alpino y el Mediterráneo. España, por su parte, está atravesada por los corredores Mediterráneo y Atlántico, que la cruzan de este a oeste. La presencia de estos corredores estratégicos que atraviesan las fronteras nacionales ha tenido efectos en los corredores de alta velocidad, pero también en la reactivación de líneas abandonadas conectadas con estas, que se han convertido en prioridades en la perspectiva de la red y, por lo tanto, en el tema de los programas y fondos especiales europeos. En este sentido, en España, un estudio llamado TREN 2020 plantea un grupo de propuestas para potenciar la oferta y la demanda del ferrocarril, a partir de un encargo de Comisiones Obreras, Greenpeace y WWF a la Asociación para la Promoción del Transporte Público (PTP), teniendo como principal objetivo optimizar la política de infraestructuras y servicios del Gobierno de España para potenciar aún más el ferrocarril. Se propone una nueva hoja de ruta basada en la combinación de planes de servicio (2013-2020) con planes de infraestructura (2013-2030). El 2020 da nombre a este proyecto al ser éste el plazo fijado por la Unión Europea para haber reducido un 20\% las emisiones de CO2 respecto a 1990.

Aquellas líneas abandonadas que cruzan territorios de valioso paisaje, con el establecimiento de servicios de trenes turísticos, incluso con vehículos históricos que han sido reestructurados, pueden constituir hoy, también, un gran recurso tanto en términos de mantenimiento de línea (tal vez pendiente de una reactivación del servicio de tren ordinario) tanto en términos de usabilidad turística de pequeños centros como de apoyo para la planificación intermunicipal de eventos e itinerarios. 
En Italia, en este sentido, desde 2014, la Fondazione FS italiane ha lanzado la iniciativa Binari senza tempo, que envolvió alrededor de $600 \mathrm{~km}$ de líneas sin servicio de transporte, que se han convertido en un museo dinámico que cruza los más lindos paisajes italianos, involucrando a unos 150.000 turistas cada año. Esta tendencia ha conducido en 2017, con la aprobación de la Ley n.128/17 "Disposizioni per l'istituzione di ferrovie turistiche mediante il reimpiego di linee in disuso o in corso di dismissione situate in aree di particolare pregio naturalistico o archeologico", al establecimiento de 18 ferrocarriles turísticos a través de la reutilización de líneas en desuso en áreas prestigiosas, también previendo la creación de nuevos espacios museísticos que, junto con la mejora de los vehículos ferroviarios históricos, permitirán enriquecer la propuesta turística del país, mejorar la movilidad sostenible y ofrecer nuevas e importantes oportunidades laborales. Como parte de las actividades de valorización de los tramos ferroviarios afectados, serán involucradas las asociaciones y organizaciones de voluntarios que trabajan en el ferrocarril, el turismo, la cultura y el medio ambiente (Amato et al., 2021).

En España, la Fundación de los Ferrocarriles Españoles (FFE), constituida en 1985, junto a las principales empresas del sector público ferroviario español, tiene encomendada la recuperación y valorización del patrimonio histórico, cultural, científico y tecnológico ferroviario. La Fundación también recoge, como se puede leer en su estatuto, el fin de “(..) desarrollar y mantener el Plan de identificación, protección y divulgación del Patrimonio Histórico y Cultural Ferroviario” (Art. 7). La Fundación también desarrolla la plataforma de turismo ferroviario TouRail, un proyecto que persigue la promoción coordinada de todas las iniciativas españolas ligadas al patrimonio ferroviario, con el fin de generar hitos atractivos como estaciones monumentales, trazados, viaductos y museos a través de los trenes turísticos.

Con respecto a las estrategias para reutilizar líneas desmanteladas, a nivel europeo, además de la integración de la movilidad en bicicleta en muchos proyectos de transporte y líneas transeuropeas (TEN-T), se han elaborado proyectos para la creación de redes para la movilidad ciclo peatonal europea, como el proyecto EuroVelo, elaborado por la Federación Europea de Ciclistas por primera vez en 1997 que incluye, en 2013, 45,000 km ya utilizables, conectando las líneas ciclo peatonales existentes de los distintos estados miembros y planificando nuevas secciones para lograr el diseño de rutas accesibles y continuas.

La FFE en España coordina, a la escala nacional, las diferentes iniciativas del Programa Vías Verdes, desarrollado desde 1993 por el anterior Ministerio de Obras Públicas, Transportes y Medio Ambiente y actualmente por el Ministerio de Agricultura, Alimentación y Medio Ambiente, en colaboración con Adif, Renfe y Feve. Un Programa en el que participan muy activamente las Comunidades Autónomas, Diputaciones y Ayuntamientos, así como grupos ciclistas, ecologistas y ciudadanos para desarrollar iniciativas de reutilización de los ferrocarriles en desuso, o que nunca llegaron a prestar servicio, con fines ecoturísticos. Estas políticas se reflejan en casos de reutilización y relanzamiento de infraestructuras en Italia y España, que serán profundizadas en nuestra investigación. Algunos casos emblemáticos van a ser ilustrados en el apartado 3.2.

\subsection{La experimentación en curso}

El creciente interés por el relanzamiento y la reutilización de las líneas de ferrocarril secundarias que atraviesan territorios frágiles, tanto desde un punto de vista físico y socioeconómico, con especial referencia a las áreas interiores de los territorios italianos y españoles, está dando lugar a una floreciente serie de buenas prácticas en diversos aspectos. Estas áreas de estudio son territorios que han experimentado una fuerte despoblación en las últimas décadas, y un fuerte abandono de los equipos de infraestructura y, en consecuencia, la falta de accesibilidad a los servicios, la posibilidad de uso de los territorios y activación de flujos turísticos. De hecho, la Investigación ha tratado de

ACE, X (XX) CC BY-ND 3.0 ES | UPC Barcelona, España | Rutas de resiliencia en Italia y Espala. Relanzamiento y reutilización de ferrocarriles en territorios frágiles. DOI: http://dx.doi.org/10.5821/ace.15.45.10369 
aquellas intervenciones que, en línea con las tres perspectivas del trabajo, han afectado o están afectando a las líneas ferroviarias infrautilizadas o desmanteladas con intervenciones para relanzar el servicio ferroviario; reactivar en clave turística y reutilizar para movilidad dulce. Se confirma el fuerte valor económico y social que estas infraestructuras tienen para las comunidades locales en la práctica ilustrada. De hecho, las intervenciones "top-down" y "bottom-up" parten a menudo de asociaciones y grupos locales que han jugado un papel fundamental en el debate sobre el futuro de las líneas, en algunos casos activando procesos que han llevado a intervenciones estructurales y duraderas, abriendo un debate público en este sentido y estimulando a las administraciones a crear sinergias y cooperaciones institucionales multinivel $u$ horizontales. Además, los casos analizados destacan cómo las intervenciones sobre estos componentes son, a menudo, catalizadoras de nuevos o renovados mecanismos de renacimiento, que inducen nuevos flujos, o nuevos usos sin precedentes del territorio, y de hecho contribuyen al objetivo común de renacimiento y regeneración de territorios frágiles.

Figura 4. Clasificación de las experiencias de estudio. Relanzamiento, reactivación, reúso

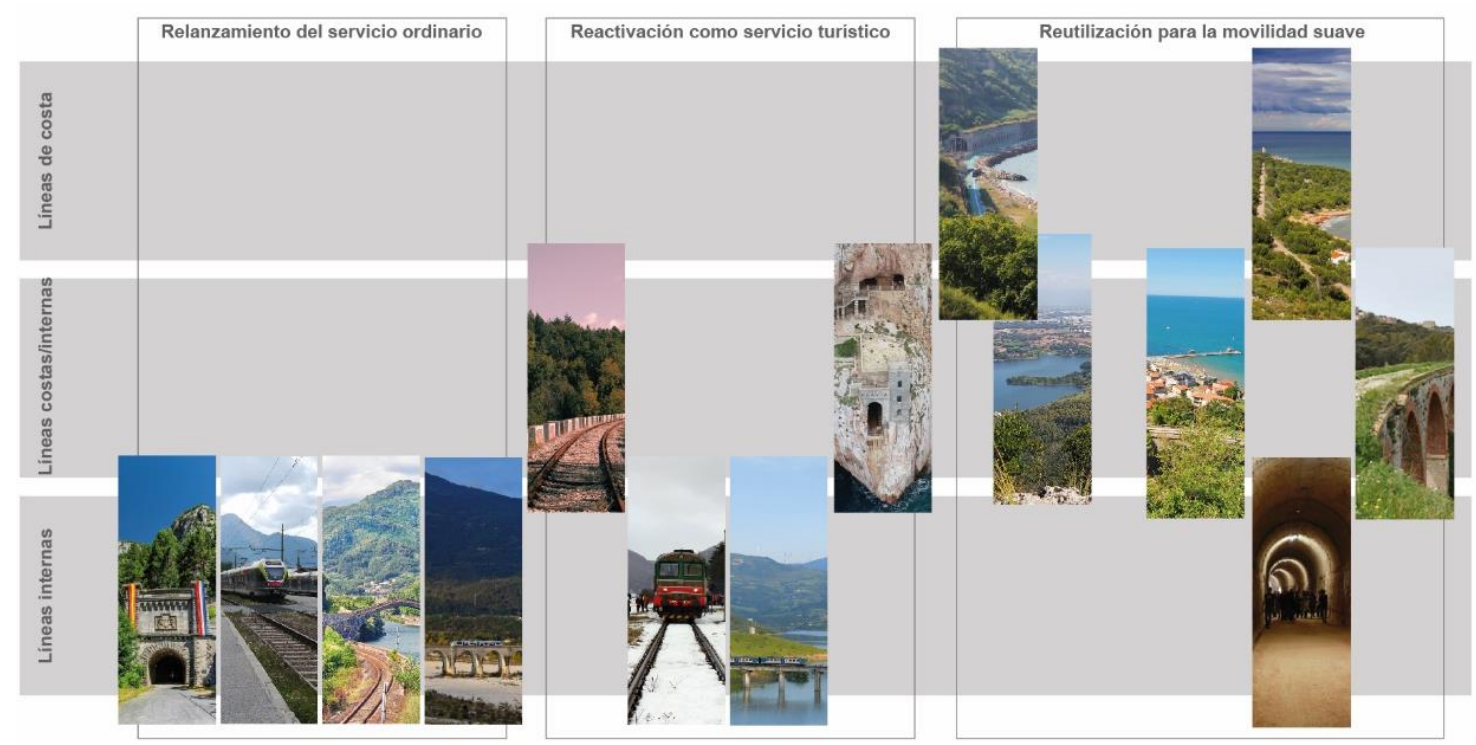

Fuente: Elaboración C. Amato.

Las buenas prácticas abordadas en la investigación son (Figura 4, de la izquierda a la derecha):

- La reactivación de la línea Zaragoza-Canfranc-Pau (Aragón y Nueva Aquitania);

- El paisaje accesible: el Tirol del Sur Südtirolbahn (Trentino Alto Adige);

- La línea Lucca-Aulla entre planificación y programación (Toscana);

- Ferrocarril Pedemontana de Friuli. Un experimento de movilidad intermodal (Friuli Venezia Giulia);

- El debate y la experimentación sobre la línea Fano-Urbino (Marche);

- El "Transiberiano" de Italia (Abruzzo);

- La línea Avellino-Rocchetta Sant'Antonio y experimentación bottom-up (Campania-Molise);

- Los Ferrocarriles del Parque Geomineral Histórico y Ambiental de Sardegna (Sardegna);

- La Via dei Trabocchi (Abruzzo);

- Le linea Velletri-Terracina (Lazio);

- La Linea Adriatica Sangritana (Abruzzo);

- La Vía Verde del Mar (Comunidad Valenciana);

- El Ferrocarril Vasco-Navarro (País Vasco); y,

- La linea Alcantara-Randazzo (Sicilia).

ACE, X (XX) CC BY-ND 3.0 ES | UPC Barcelona, España | Rutas de resiliencia en Italia y Espala. Relanzamiento y reutilización de ferrocarriles en territorios frágiles. DOI: http://dx.doi.org/10.5821/ace.15.45.10369 


\section{ACE Architecture, City and Environment}

E-ISSN 1886-4805

\section{- La línea Zaragoza-Canfranc-Pau}

En una perspectiva estructural de regeneración de las "inner peripheries", los contextos montañosos transfronterizos, marginales son casos emblemáticos “por excelencia”, como el área de los Pirineos, teatro de la reactivación de la línea ferroviaria internacional Zaragoza-Canfranc-Pau, que atraviesa la Comunidad Autónoma española de Aragón y la región francesa de Nueva Aquitania. Inaugurada en 1928 por el Rey de España y el Presidente de la República Francesa, representó una intervención importante para la red infraestructural transfronteriza, capaz de facilitar los intercambios entre España y Francia y el paso de viajeros por los Pirineos.

La longitud total de la línea, de $307 \mathrm{~km}$, se divide en un tramo español de $214 \mathrm{~km}$, desde Zaragoza hasta Canfranc, y uno francés de 93 km entre Canfranc y Pau (Ravagnan, 2019). La estación de Canfranc (Figura 5), completada junto con la línea en 1928, fue el principal punto de acceso a España desde Francia y hoy representa un lugar de memoria y calidad arquitectónica (que en la actualidad está reconvirtiéndose en un hotel junto con la creación de una nueva estación). El servicio fue interrumpido por tramos sucesivos desde la década de 1970 hasta la década de 1980, por un accidente y por la competitividad del transporte automóvil.

\section{Figura 5. Canfranc en los Pirineos}

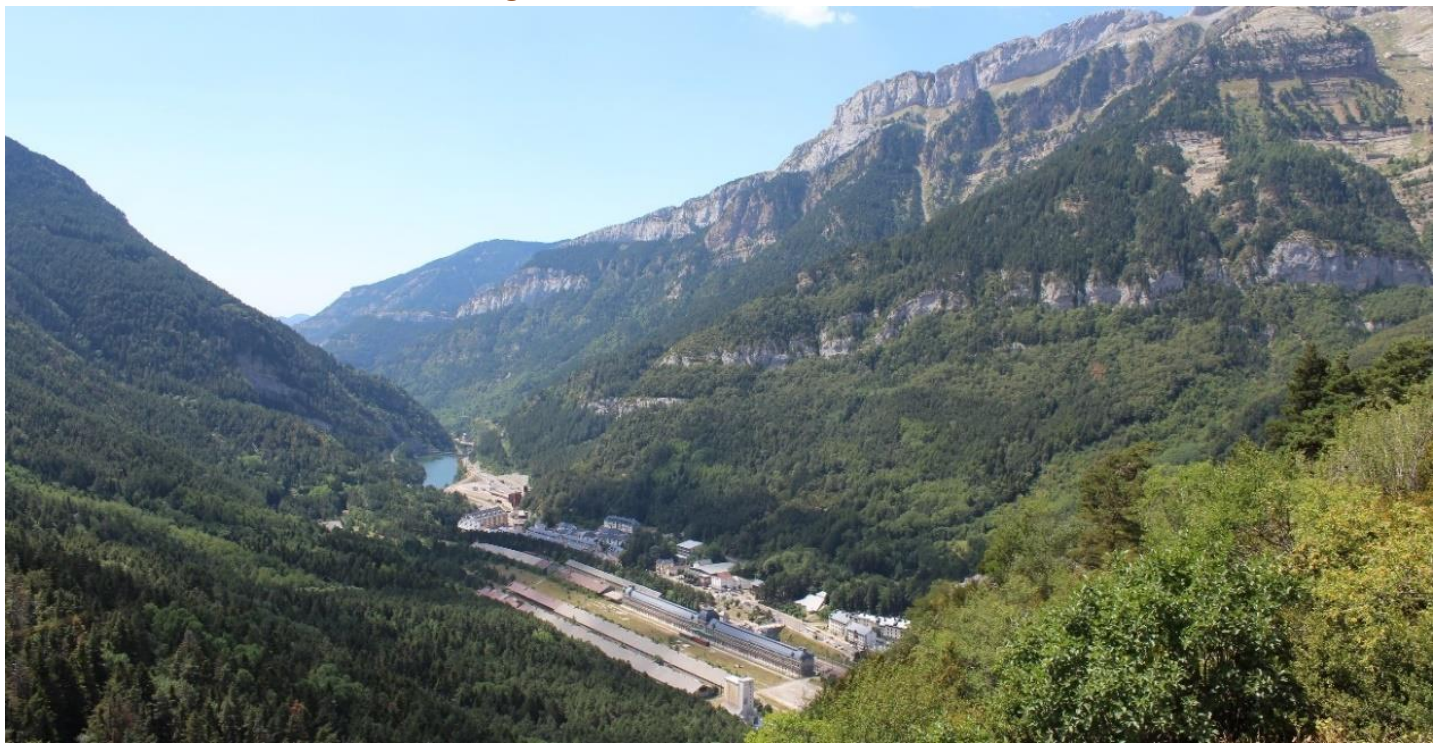

Fuente: iStock.com /CrisRb.

Además la característica transfronteriza ha influido en el destino de la línea, vinculándola con los eventos de la Guerra Civil Española y con las dinámicas políticas España-Francia, pero también ha significado que, a partir de 2000, la reapertura de la línea se convertiría en un objetivo transversal de organismos territoriales institucionales, Ministerios, Regiones, representantes del sector socioeconómico (Cámara de Comercio, Asociaciones Comerciales, Confederaciones de empresarios) y ciudadanos. La reapertura de la línea permite el transporte de mercancías entre las dos naciones a través del ferrocarril, que actualmente cubre solo el 3.2\% del total contra el paso de unos veinte mil camiones al día, con las consiguientes cuestiones de seguridad, congestión, contaminación acústica y emisiones de $\mathrm{CO}^{2}$. Además, la línea tiene una característica estratégica ante una eventual independencia del País Vasco y/o Cataluña de España.

ACE, X (XX) CC BY-ND 3.0 ES | UPC Barcelona, España | Rutas de resiliencia en Italia y Espala. Relanzamiento y reutilización de ferrocarriles en territorios frágiles. DOI: http://dx.doi.org/10.5821/ace.15.45.10369 


\section{ACE Architecture, City and Environment}

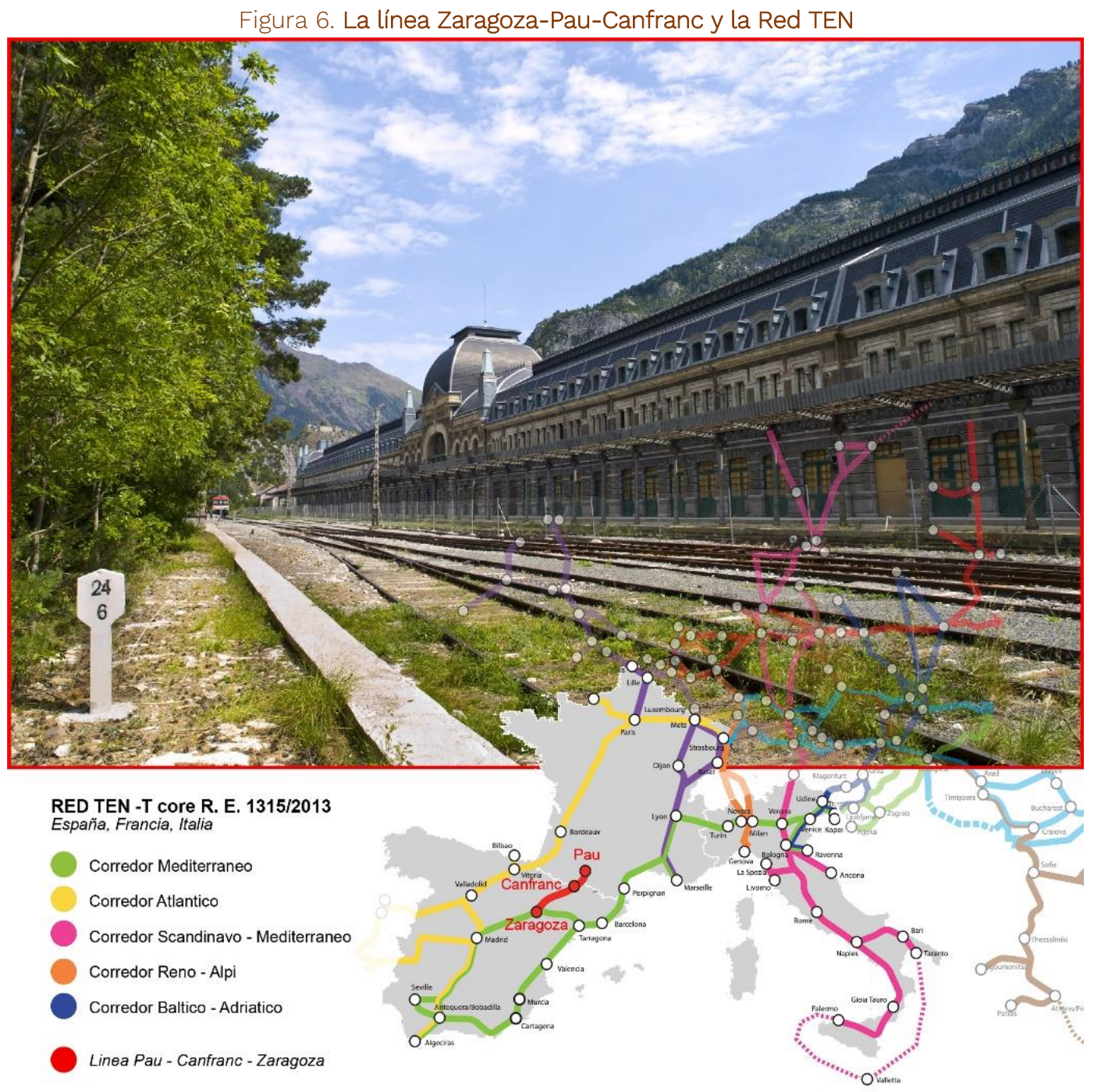

Fuente: Elaboración propia. Foto: iStock.com/Somatuscani.

El proyecto, apoyado a nivel europeo a través del FEDER para mejorar la accesibilidad de los Pirineos, lleva a cabo efectivamente el tercer paso entre los dos corredores prioritarios de la TEN-T (Figura 6), el Corredor Atlántico al oeste y el Corredor Mediterráneo al este. En este marco de referencia, dentro del Programa Operativo de Cooperación Territorial entre España-Francia-Andorra (POCTEFA INTERREG IV A, 2007-2013 y 2014-2020), el Gobierno de Aragón y el Consejo Regional de Aquitania han presentado el proyecto conjunto Canfraneus y Canfraneus II, destinado a restablecer el tráfico ferroviario en la línea. La reapertura en 2016, de un primer tramo en Francia entre Olorón y Bedous es la expresión tangible del deseo de proceder a la reapertura de toda la línea. La intervención posterior, que prevé la restauración, por parte del gobierno español, del tramo Huesca - Canfranc, para 2020, sancionada por un protocolo entre Aquitania y Aragón, concreta el primer objetivo del proyecto: mejorar el servicio de transporte dirigido a los viajeros y, al mismo tiempo, fomentar el uso de la línea ferroviaria con fines comerciales. Por lo tanto, el caso de la reactivación de esta línea muestra una voluntad compartida por todos los niveles institucionales para estructurar una red de transporte integrada entre grandes corredores ferroviarios y líneas de conexión transversales, facilitando el desarrollo económico y turístico sostenible en áreas transfronterizas, como los

ACE, X (XX) CC BY-ND 3.0 ES | UPC Barcelona, España | Rutas de resiliencia en Italia y Espala. Relanzamiento y 13 reutilización de ferrocarriles en territorios frágiles. DOI: http://dx.doi.org/10.5821/ace.15.45.10369 
peregrinos hasta Santiago de Compostela, y protegiendo los contextos más frágiles, como el de la Valle de Aspe, un importante corredor ecológico.

\section{- La línea Avellino-Rocchetta Sant'Antonio}

Con respecto al relanzamiento del servicio ferroviario en una perspectiva morfológica, que se ocupa del tren en su conjunto y del paisaje atravesado, la línea Avellino - Rocchetta Sant'Antonio es uno de los ferrocarriles turísticos más prestigiosos enumerados en la Ley 128/2017. La linea de ferrocarril de $120 \mathrm{~km}$ atraviesa el territorio rico en historia, cultura y paisajes de Irpinia (Figura 7). El camino, muy tortuoso, cruza tres regiones, Campania, Basilicata y Puglia, a través de un territorio frágil y un paisaje caracterizado por pueblos casi abandonados, emblemáticos de la dinámica que afecta a las áreas internas. La línea, inaugurada en 1895, conectaba Avellino con la constelación de pequeños pueblos construidas a lo largo de los valles de los ríos Sábado, Calore y Ofanto, ejes de conexión antes del advenimiento del ferrocarril. Pero la ausencia de su inserción real en una red infraestructural y la falta de conexiones cruzadas con el contexto circundante, junto con el auge del automóvil y la construcción de la Carretera Nápoles-Bari, hizo progresivamente que se vaciase el área de influencia del ferrocarril.

Figura 7. La línea Avellino-Rocchetta-Sant’Antonio en el Lago de Conza

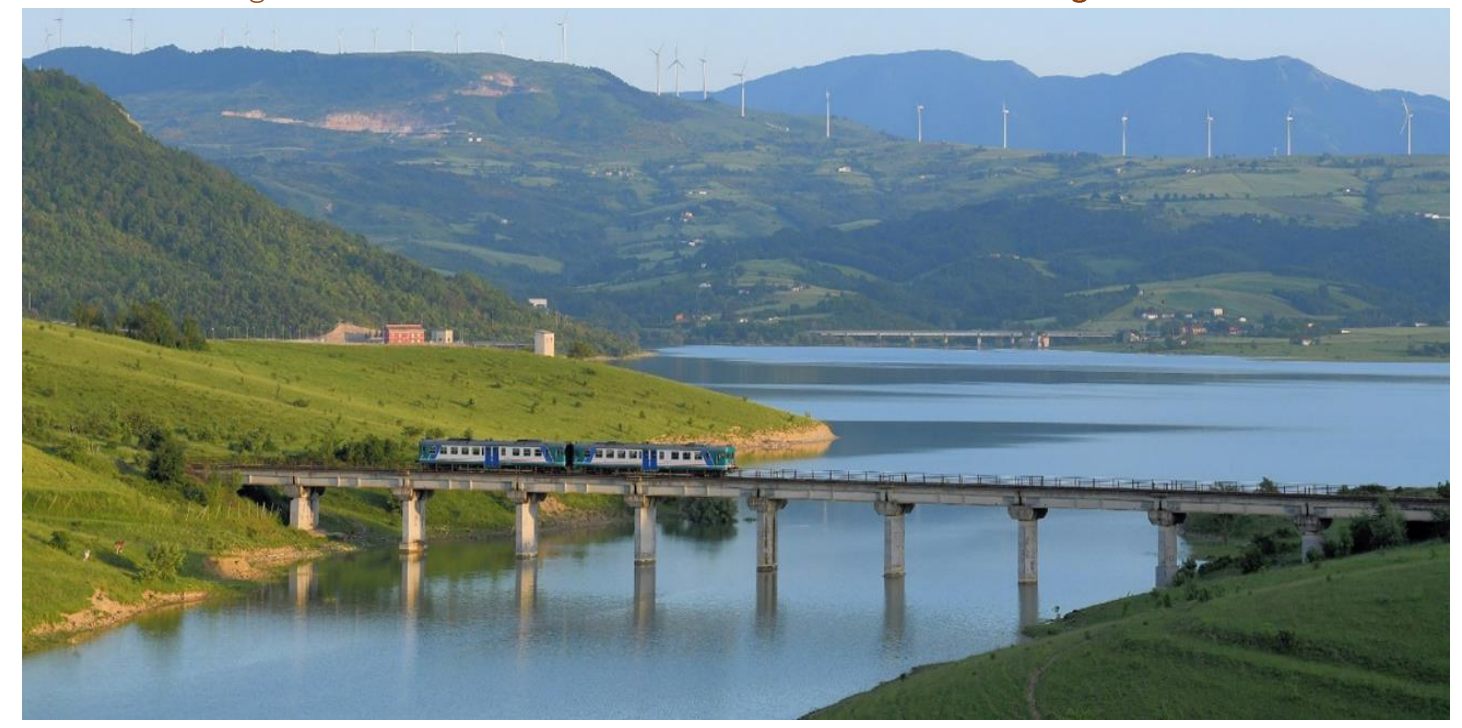

Fuente: Andrea Terrevoli.

El éxodo de la población de Irpinia desde la década de 1950, el terremoto de 1980 que causó 3.000 muertes y 280.000 personas desplazadas junto con un importante daño a la línea, además de las políticas de inversión en transporte por carretera, llevaron a la suspensión definitiva de la línea en 2010. Pero, por el fuerte valor histórico y el paisaje único que la línea atraviesa, desde 2007, la asociación Treni di Irpinia puso a disposición trenes turísticos para llegar a los pueblos durante eventos, destacando el potencial turístico de la línea. En 2009, una red de asociaciones (Amici della Terra Irpina, Irpinia Turismo, RossoFisso, Irpinando), organizaciones y ciudadanos, junto con el Observatorio CGIL, crearon la asociación In_Loco_Motivi, para la recuperación y mejora de la línea, manteniendo una importante tensión a través de la participación en eventos a escala nacional, como el Día Nacional de los Ferrocarriles Olvidados. En la propuesta de estructura estratégica contenida en el PTCP Avellino 2014, la línea ferroviaria aparece como una "ruta de movilidad sostenible de interés histórico, arquitectónico y paisajístico de valor territorial" y se incluye entre los proyectos y programas considerados prioritarios para la consecución de los objetivos del Plan. La acción prevista se refiere

ACE, X (XX) CC BY-ND 3.0 ES | UPC Barcelona, España | Rutas de resiliencia en Italia y Espala. Relanzamiento y reutilización de ferrocarriles en territorios frágiles. DOI: http://dx.doi.org/10.5821/ace.15.45.10369 
a la adaptación de la línea ferroviaria y su promoción como ruta de interés turístico, a través de un acuerdo entre la Provincia, la Región, la Autoridad Ferroviaria, los municipios, las comunidades y los operadores económicos. En 2015, gracias a un acuerdo interinstitucional, la línea se incluye en el proyecto Binari senza tempo, también gracias a la estrecha relación con la Ciclovia dell'acqua que conecta Caposele con Santa Maria di Leuca, parte del Sistema Nacional de Cicloturismo Turístico.

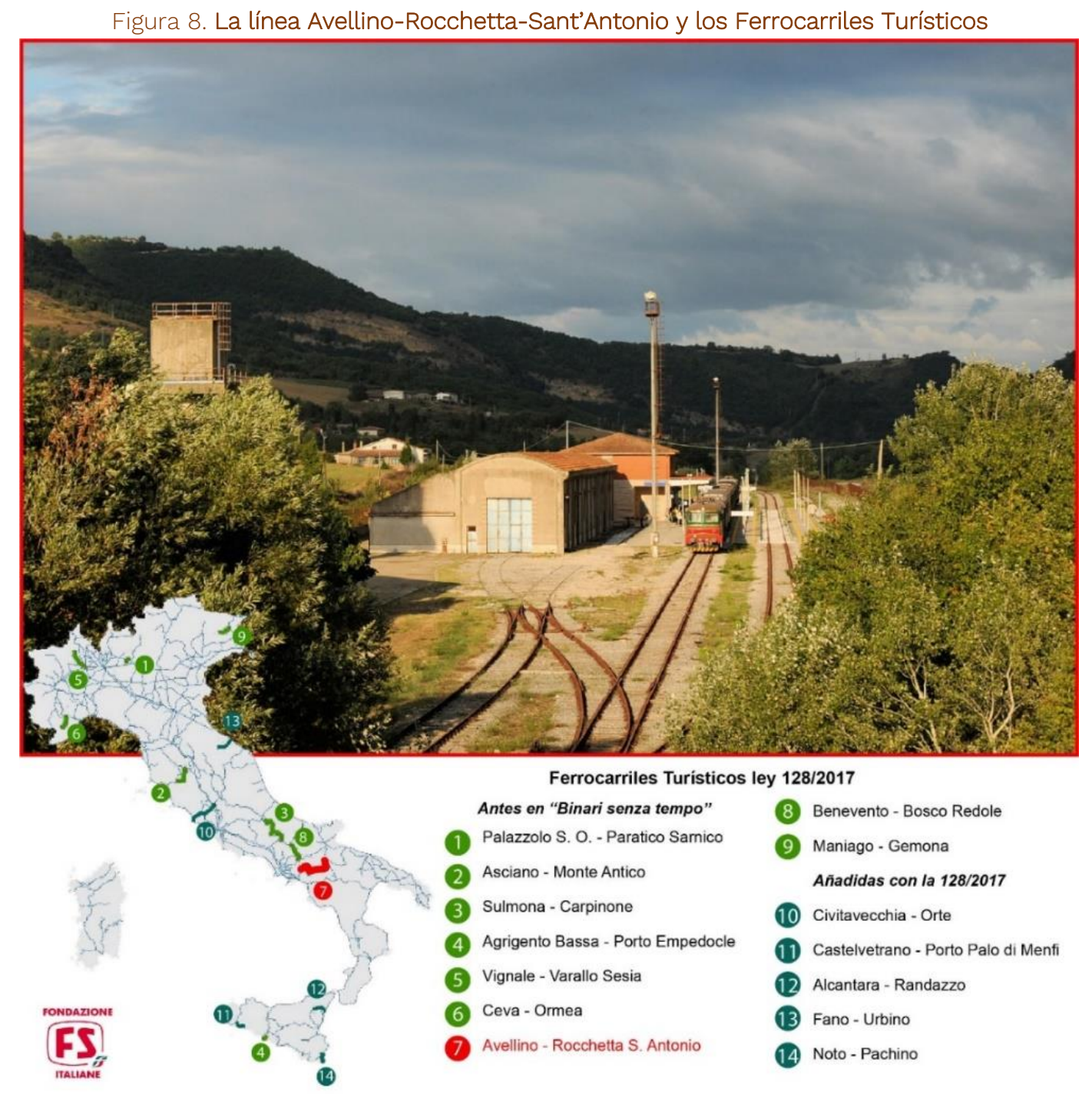

Fuente: Elaboración propia. Foto: Andrea Terrevoli.

Estas actividades le dieron a la línea una nueva identidad e importancia territorial, y gracias a estas iniciativas y al compromiso de las asociaciones involucradas, la línea se incluyó en la lista de la ley 128/2017 (Figura 8). Hasta la fecha, se han restaurado los 120 km de línea y, a lo largo de las vías, circulan trenes turísticos. Un proyecto hecho posible por la sinergia entre las autoridades locales, la Fundación FS y la región de Campania. La línea Avellino-Rocchetta San Antonio representa un caso emblemático, debido a la fragilidad multisectorial del territorio que atraviesa, pero que hoy está buscando un cambio radical, convirtiéndose en el líder de nuevas prácticas de reutilización y participación, visibles en el papel de Alta Irpinia en el SNAI (Alta Irpinia es la única de las 68 áreas piloto seleccionadas para incluir un Plan de Transporte de Áreas Internas) y por la coherencia

ACE, X (XX) CC BY-ND 3.0 ES | UPC Barcelona, España | Rutas de resiliencia en Italia y Espala. Relanzamiento y 15 reutilización de ferrocarriles en territorios frágiles. DOI: http://dx.doi.org/10.5821/ace.15.45.10369 
interinstitucional que este proyecto ha visto converger (Contarino y Von Normann, 2018) a partir de las comunidades y asociaciones de ciudadanos. Un hilo conductor que une proyectos de movilidad sostenible, leyes nacionales sobre ferrocarriles turísticos, planificación de grandes áreas, en un marco de coherencia que hizo posible que esta infraestructura desempeñara un papel portador de nuevas economías y valores.

\section{- La Vía Verde dei Trabocchi}

Es posible caracterizar en una perspectiva "ecológica" numerosas experiencias de reutilización de las líneas ferroviarias que surgen en zonas de fragilidad medioambiental. En Italia, una experiencia emblemática en curso es la Vía Verde de la Costa dei Trabocchi, una ruta de 40 kilómetros a lo largo de la costa adriática de Abruzzo que resulta de la reutilización de la línea de ferrocarril Ancona-Lecce en el tramo Ortona-Vasto y que ha sido reconocida como una oportunidad estratégica para la regeneración de la franja costera. El proyecto surge del desmantelamiento de la línea ferroviaria que entró en servicio en 1864 y fue abandonada en fases diferentes, entre 1985 y 2005, tras la construcción de una variante de trazado, construida más internamente, a causa de la fragilidad medioambiental que implicaba altos costos de gestión, dificultad en la rehabilitación y potencial de valorización costera (Amato et al., 2019).

El proyecto de la green way tiene sus raíces en el Proyecto territorial especial de la costa teatina, previsto por el Plan Territorial General Provincial de Chieti (2002), en conformidad con el Quadro di Riferimento Regionale (2000) y con el Art.41 Misure di tutela ambientale connesse alla dismissione di tratte ferroviarie de la Ley Regional 38/96 (modificado con la Ley Regional 5/07) que garantiza la protección de las áreas alrededor del antiguo ferrocarril, originalmente imaginado como un posible ferrocarril turístico.

La Ley Regional n. 5/07 identifica en este ámbito territorial un "Sistema de Áreas Protegidas de la Costa Teatina” y configura la realización de la Vía Verde como un proyecto estructurante. El Proyecto preliminar de la green way se aprobó en 2009, llegando a ser parte del Documento programmatico del Progetto territoriale speciale della fascia costiera (2010) y del Protocollo di intesa per la realizzazione della Via Verde della Costa dei Trabocchi, estipulado entre la Rete Ferroviaria Italiana RFI, Ministerios, Región, Provincia, Municipios (y otros actores) en 2011.

El Protocolo sanciona la disponibilidad de la RFI para la cesión de las áreas a título oneroso y el financiamiento con el Fondo Aree Sottoutilizzate (hoy FSC) por el Ministero dello Sviluppo Economico, sentando las bases el proyecto ejecutivo de la "Vía verde della Costa dei Trabocchi" (2017), ahora en ejecución. La construcción de la ruta es parte del proceso de construcción de la Ciclovía Adriática que, en el marco de las 10 Ciclovie turistiche nazionali, se planifica desde Venezia hasta el Gargano a lo largo de $700 \mathrm{~km}$ de franja costera. El camino coincide con la rama no 6 de la red nacional Bicltalia - en parte en la fase de diseño y en parte ya implementada - que se conecta con la red EuroVelo (Figura 9).

En mayo de 2019, se firmó un Protocollo di intesa para el diseño y la construcción de la ruta ciclista turística del Adriático, entre el Ministero delle Infrastrutture e dei Trasporti (MIT) y las Regiones de Marche (líder), Véneto, Emilia-Romagna, Molise, Puglia y Abruzzo. Para la finalización de esta ruta hay una primera asignación presupuestaria de 19 millones de euros, y la sección de Abruzzo ha sido confirmada como la más avanzada en la construcción de la Ruta Adriática: 86 km a lo largo de 131 km. Además de insertar las ciclovías en una política de movilidad sostenible, y de promover el uso de bicicletas en general, con la red de rutas ciclistas turísticas, el MIT tiene la intención de contribuir al desarrollo del ciclismo como impulso a la regeneración de los territorios atravesados.

ACE, X (XX) CC BY-ND 3.0 ES | UPC Barcelona, España | Rutas de resiliencia en Italia y Espala. Relanzamiento y reutilización de ferrocarriles en territorios frágiles. DOI: http://dx.doi.org/10.5821/ace.15.45.10369 


\section{ACE Architecture, City and Environment}

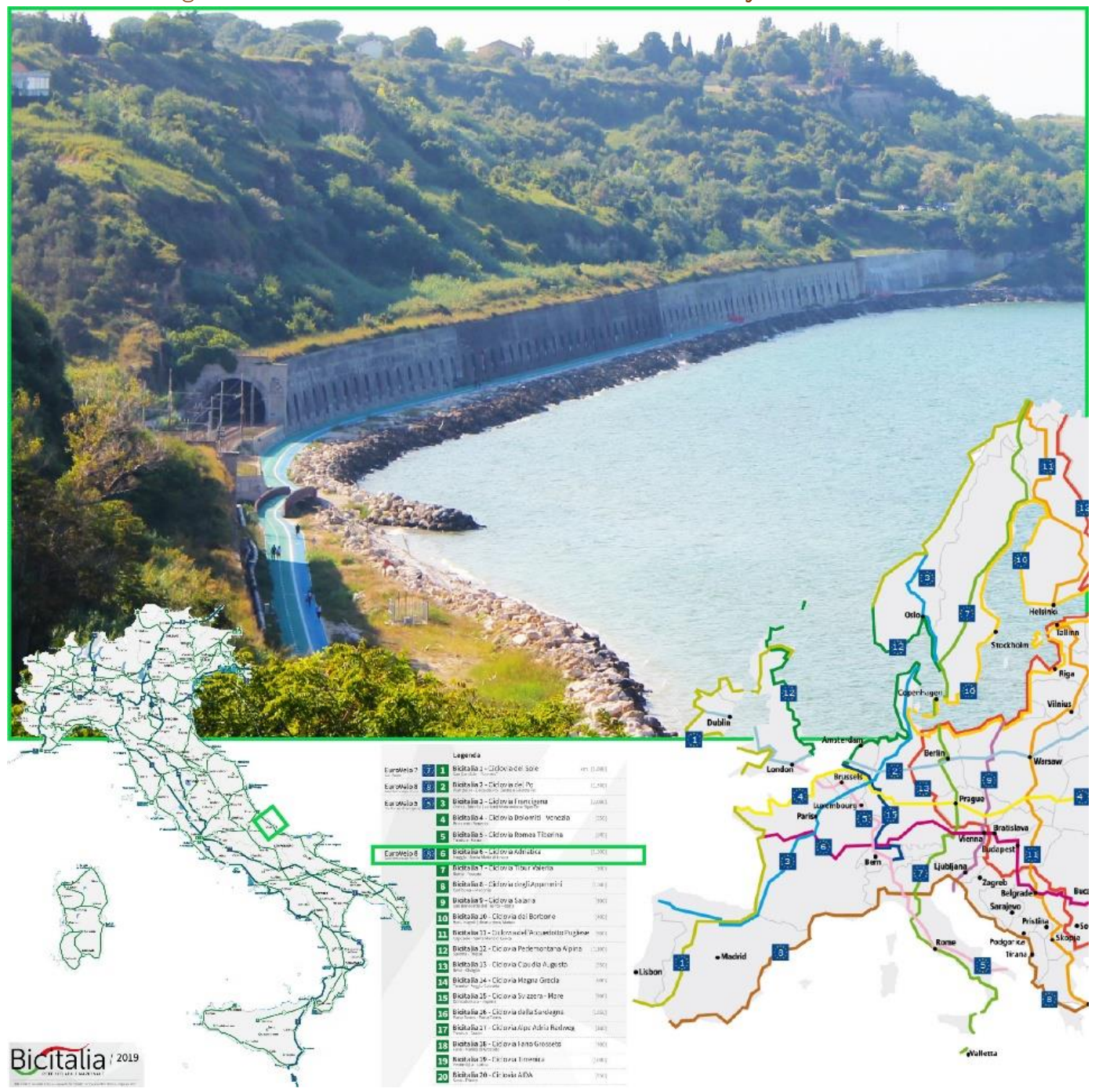

Fuente: Elaboración propia, 2019. Foto: Chiara Ravagnan

Las intervenciones dirigidas a la reutilización de la línea ferroviaria también han desencadenado acciones para restaurar y proteger los acantilados sujetos a una fuerte erosión y sifonamiento, regeneración del hábitat de las plantas autóctonas, contrarrestando los fenómenos de deslizamientos de tierra y la degradación ambiental. La green way también soporta la "accesibilidad universal" de un bien común como la costa de Abruzzo, desarrollándose entre el mar y la colina que limita el acceso a la playa y a los landmarks diseminados en un paisaje de inestabilidad hidrogeológica. De hecho, la costa está salpicada de componentes de valor histórico y de identidad que enriquecen un sistema de promontorios. Entre otros, los Trabocchi, íconos de la fragilidad de la costa y, al mismo tiempo, elemento de continuidad para un posible renacimiento de este territorio a partir de una reconfiguración de las relaciones funcionales, morfológicas y ecológicas (Amato et al., 2019).

\section{- La Vía Verde del Mar}

En la costa valenciana hay un caso emblemático, comparable al que se está desarrollando a lo largo de la costa teatina, en el marco de un contexto nacional y regional fuertemente encaminado a incorporar las directrices medioambientales en términos de infraestructuras verdes: la Vía Verde del

ACE, X (XX) CC BY-ND 3.0 ES | UPC Barcelona, España | Rutas de resiliencia en Italia y Espala. Relanzamiento y reutilización de ferrocarriles en territorios frágiles. DOI: http://dx.doi.org/10.5821/ace.15.45.10369 


\section{ACE Architecture, City and Environment}

E-ISSN 1886-4805

Mar (Figura 10). Una oportunidad para la regeneración territorial, en algunos casos de gran valor ambiental y paisajístico, que se desencadena por la disposición gradual y generalizada de las redes ferroviarias de vía estrecha a lo largo de las zonas costeras. El progreso tecnológico, junto con la mayor conciencia de la calidad y la fragilidad de los contextos ambientales fue, de hecho, la causa del proceso masivo de eliminación que afectó a este tipo de línea ferroviaria a partir de la segunda mitad del siglo XX, para eliminar los medios de transporte lentos y obsoletos, con consecuencias negativas para las economías y las comunidades locales que éstos conectaban (Ravagnan y Amato, 2020).

Figura 10. La Vía Verde del Mar, Vías Verdes y Eurovelo

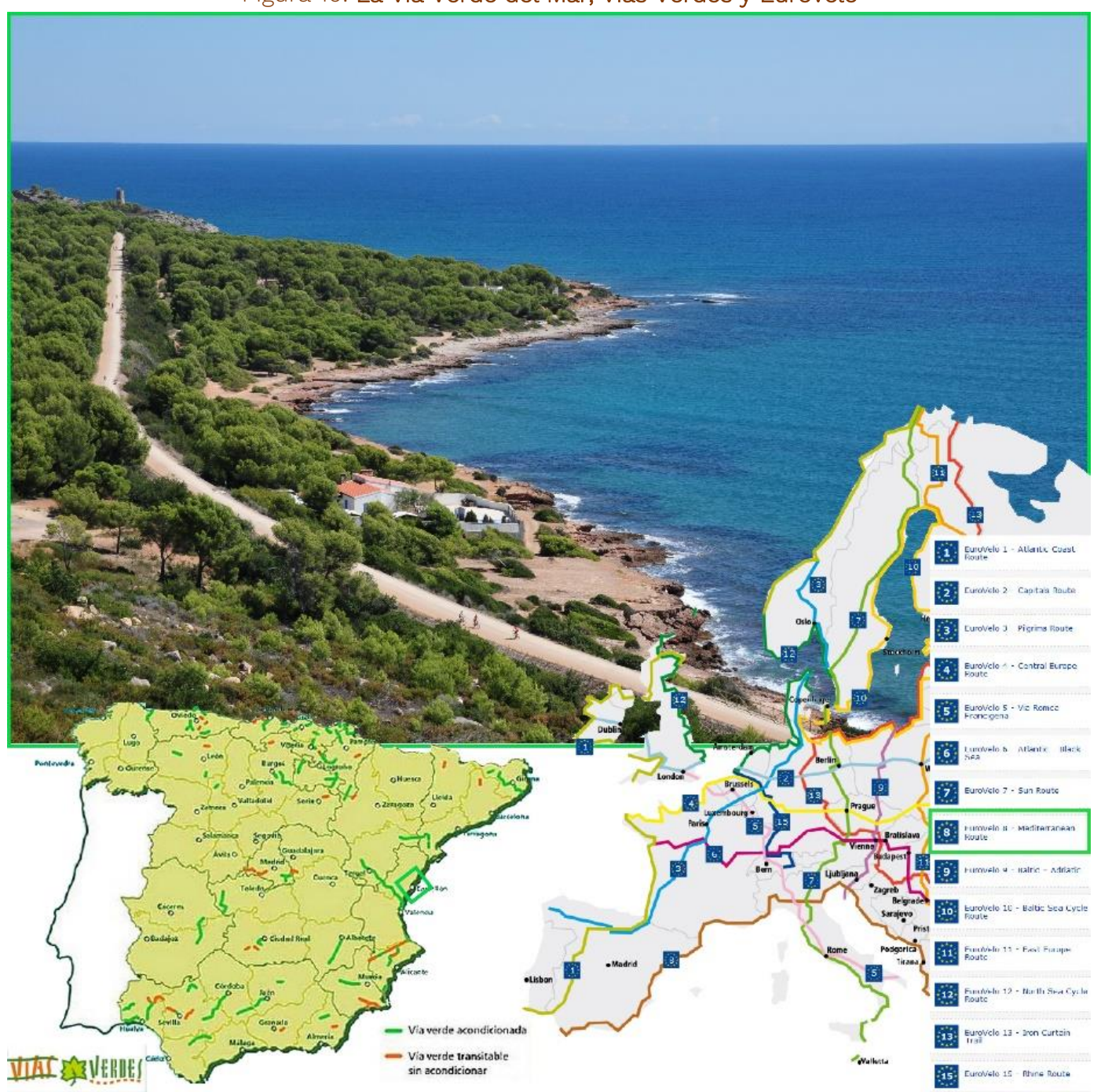

Fuente: Elaboración propia. Foto: iStock.com/Vicenfoto.

En la Comunidad Autónoma Valenciana, un caso de estudio de particular interés ambiental y paisajístico es la Vía verde del Mar, en el municipio de Oropesa del Mar, en la Provincia de Castellón. Como en el caso de la Vía Verde dei Trabocchi, la ruta discurre entre una zona montañosa, la Sierra de Oropesa, y el mar, utilizando algunas "obras titánicas" creadas para el paso del ferrocarril, que hoy constituyen componentes de identidad: pasajes en trincheras, túneles, puentes metálicos. El ferrocarril, que forma parte de la ruta Barcelona-Valencia, se construyó a finales del siglo XIX en una fase $\sin$ sensibilidad al contexto de alto valor natural y paisajístico. La variante de trazado, requerida

ACE, X (XX) CC BY-ND 3.0 ES | UPC Barcelona, España | Rutas de resiliencia en Italia y Espala. Relanzamiento y 18 reutilización de ferrocarriles en territorios frágiles. DOI: http://dx.doi.org/10.5821/ace.15.45.10369 
por la necesidad de aumentar la velocidad en este tramo, llevó a la construcción de la Vía Verde del Mar en 2008-2009 impulsada por el Ministerio de Fomento, como compensación ambiental por la construcción de la variante. La reutilización de estas vías ferroviarias, que, en las primeras décadas, tuvo lugar solo por tramos, ahora encuentra un enfoque de planificación territorial de gran interés en la construcción de una Infraestructura verde objeto del Plan de Acción Territorial de la Infraestructura Verde del Litoral (PATIVEL). El PATIVEL es un instrumento de planificación del territorio supramunicipal, al que se refiere el artículo 16 de la Ley 5/2014 (LOTUP) de la Generalitat, relativa al Gobierno del territorio, la Planificación Urbana y el Paisaje, que puede adoptar un carácter sectorial o integrado, basado en las peculiaridades temáticas y el área territorial identificada.

En el caso del PATIVEL, se explica una dimensión territorial que traduce una instancia de integración entre los aspectos urbanos, ambientales y paisajísticos, en la construcción de una infraestructura costera verde. Este instrumento adquiere el carácter de plan territorial con el objetivo de superar un enfoque puramente cuantitativo y de protección, a fin de preservar unas continuidades paisajísticas e infraestructurales estratégicas, aunque menos valiosas que las áreas naturales protegidas; al mismo tiempo, sugerir oportunidades de desarrollo socioeconómico para la zona costera, en línea con la Estrategia Territorial de la Comunidad Valenciana (Decreto 1/2011). En particular, el PATIVEL asocia objetivos para reducir el consumo de suelo con medidas de mejora del paisaje. En el caso de la Vía Verde del Mar, el PATIVEL prevé no solo la conexión en red del tramo de la vía verde con un corredor costero ciclista peatonal, sino que prescribe la no construcción de las áreas circundantes, preservando la conexión ecológica y la continuidad del paisaje entre la colina y el mar.

\section{Conclusiones. Perspectivas y referencias para la experimentación}

\subsection{Referencias metodológicas}

El análisis de los datos disponibles en los casos de estudio resalta las diferentes connotaciones de fragilidad de los territorios investigados (pérdida de accesibilidad, despoblamiento, inseguridad e insuficiencia de los trazados) y la potencialidad de los ferrocarriles en desmantelamiento en las "aree interne".

A los efectos de una propuesta metodológica, la fase conclusiva de la investigación planteó algunos referentes para identificar las líneas de intervención, a partir de la conciencia del potencial significativo de estas líneas, surgidas tanto del análisis de las políticas generales (Vías verdes en España, SNAI en Italia), como de la profundización de los casos de estudio de las líneas ferroviarias en desuso en Italia y España, que ofrece una visión general de las relaciones entre estos dos campos de investigación y convergencia de objetivos. De hecho, el análisis de los casos destaca, según una metodología inductiva, no solo el vínculo entre los fenómenos de abandono y desmantelamiento de infraestructuras, sino también la centralidad del relanzamiento y reutilización de líneas en desuso en las Estrategias de Área (SNAI), Planes Territoriales, Planos estructurales y paisajísticos.

En esta fase de recomposición de las referencias, el análisis de la RFI disponible y de los datos de Ferrovie abbandonate también permitió una clasificación de los tramos suspendidos, infrautilizados y en desuso (que entran dentro de la definición de líneas desmanteladas), con el fin de aclarar, a la luz del análisis de los estudios de caso, las características "endógenas" relacionadas con los tipos de infraestructura y las características "exógenas" relacionadas con el contexto territorial.

Por vías de infraestructura entendemos la identificación de algunas macro-categorías de líneas ferroviarias en desmantelamiento, analizando como elemento diferencial la característica de la línea y por tanto el método de disposición al que fue sometida. De hecho, a través del estudio de las

ACE, X (XX) CC BY-ND 3.0 ES | UPC Barcelona, España | Rutas de resiliencia en Italia y Espala. Relanzamiento y 19 reutilización de ferrocarriles en territorios frágiles. DOI: http://dx.doi.org/10.5821/ace.15.45.10369 
experiencias, fue posible delinear tres categorías principales que corresponden a diferentes factores que han representado una criticidad para el uso de la línea, y que han marcado su abandono, y que hoy, sin embargo, pueden ser reinterpretadas en una nueva clave estratégica como punto de partida para una reinterpretación de las rutas, y por tanto para una reutilización de este en una estrategia unitaria de regeneración. En este sentido, desde una perspectiva resiliente, no cabe duda de que algunos factores técnicos endógenos a la propia línea, como las características del ancho de las vías, la obsolescencia de los componentes ferroviarios y la utilidad de transporte de la ruta, pueden orientar la definición de prioridades, y los métodos de intervención (Figura 11). Las categorías son:

a) Líneas de ancho ordinario con servicio suspendido: esta primera categoría constituye un gran porcentaje de los activos en enajenación del país, aproximadamente el 42\%, lo que corresponde a $3.600 \mathrm{~km}$ de líneas abandonadas a lo largo de toda la península italiana. La suspensión del servicio en líneas de ancho ordinario no debe contabilizarse con mucha frecuencia como un problema relacionado con la capacidad de carga de la línea o con algunos componentes obsoletos de la ruta, sino con la dinámica existente en los territorios atravesados, "rami secchi" que han ligado su destino al de los espacios interiores y que han sido olvidados con ellos.

b) Líneas con servicio suspendido de vía estrecha: la segunda categoría se refiere a las líneas con servicio suspendido y de vía estrecha: estas representan una parte del patrimonio ferroviario italiano abandonado igualmente importante que las de ancho ordinario, el 38\% del total, correspondiente a $3250 \mathrm{~km}$ abandonados.

c) Variantes de trazados (y las líneas inconclusas): la tercera y última categoría se refiere a las líneas abandonadas siguiendo una variante del recorrido y las líneas inacabadas; que en conjunto en Italia constituyen el $20 \%$ de las líneas abandonadas, el $14 \%$ de las variantes de ruta (correspondientes a aproximadamente $1200 \mathrm{~km}$ ) y el 6\% de las líneas sin terminar (o aproximadamente $570 \mathrm{~km}$ ).
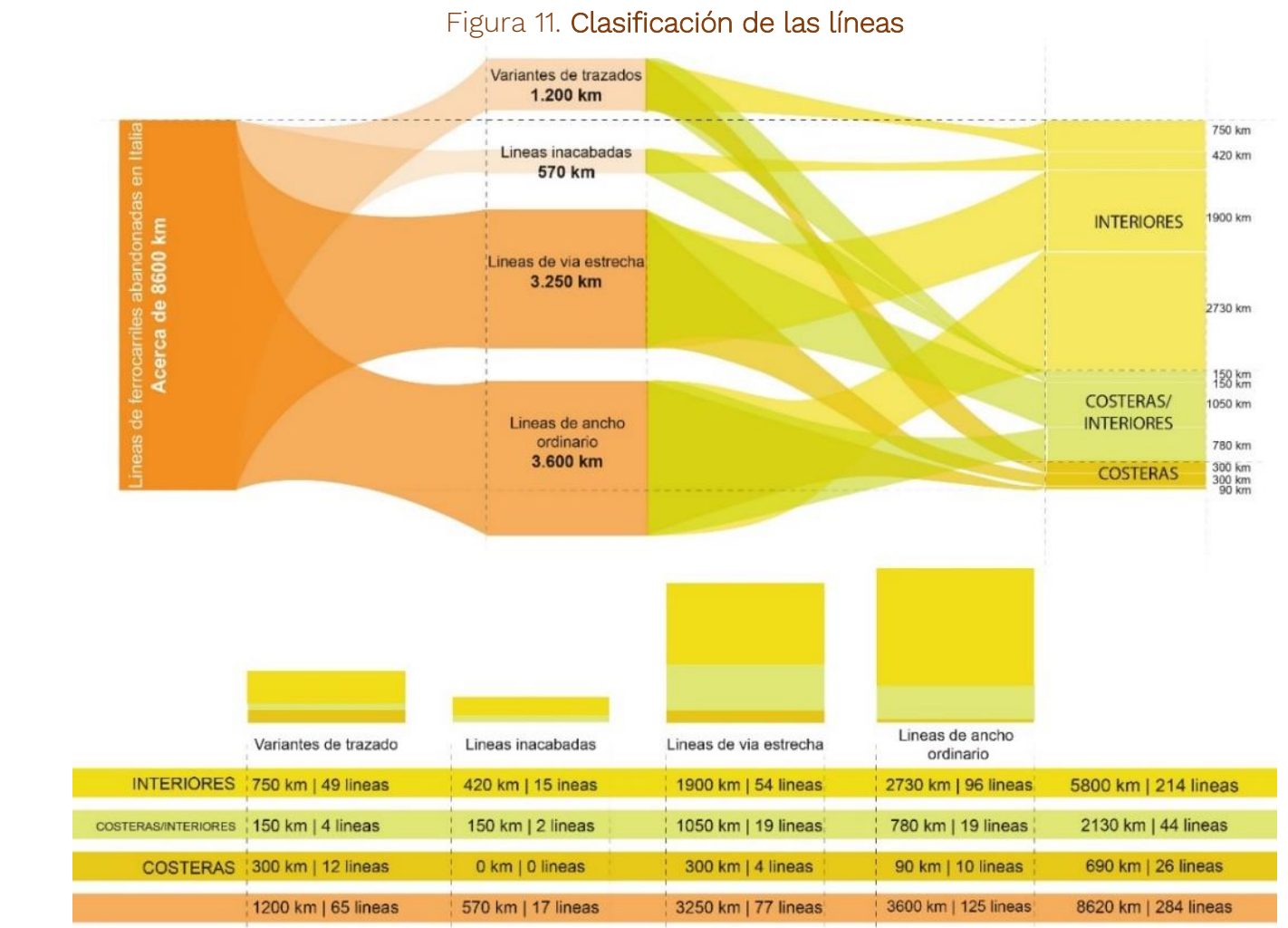

Fuente: Elaboración autor, utilizando datos de www.ferrovieabbandonate.it.

ACE, X (XX) CC BY-ND 3.0 ES | UPC Barcelona, España | Rutas de resiliencia en Italia y Espala. Relanzamiento y reutilización de ferrocarriles en territorios frágiles. DOI: http://dx.doi.org/10.5821/ace.15.45.10369 
El proceso de profundización también propone una clasificación de rutas territoriales que se configuran como pautas territoriales privilegiadas definidas por relaciones específicas entre las líneas ferroviarias y los elementos estructurales del territorio. Reflejan, por tanto, huellas, vínculos que unen partes del territorio que, como resultado del estudio de las experiencias realizadas hasta el momento, parecen ser más determinantes a nivel territorial para la construcción de caminos de resiliencia tanto en la accesibilidad de los espacios interiores, como en el perfil de la puesta en valor de los sistemas naturales e históricos, y de la construcción de infraestructuras verdes en zonas de gran fragilidad ambiental (Figura 12). Las rutas territoriales se articulan en:

a) Líneas costeras, que representan en Italia el 8\% del total de líneas abandonadas (unos $690 \mathrm{~km}$ en total) pero el $25 \%$ de las líneas abandonadas siguiendo una variante de ruta (unos $300 \mathrm{~km}$ ). Su característica concierne principalmente a los motivos que subyacen al abandono, que están relacionados con la fragilidad de los territorios costeros y por tanto a la variante del recorrido por riesgo hidrogeológico (deslizamientos, sifones) pero también al carácter de barrera que estas líneas tienen en la relación entre costa y territorio, y por tanto impidiendo el acceso a la costa.

b) Las líneas interiores/costa: las líneas transversales que atraviesan los territorios que conectan la costa con el interior representan en Italia el 25\% del total de líneas abandonadas, unos $2130 \mathrm{~km}$. El 49\% de ellos (alrededor de $1050 \mathrm{~km}$ ); son líneas de vía estrecha, es decir, las que en las rutas infraestructurales se han definido como líneas obsoletas, con caminos tortuosos; El 36\% del total, un porcentaje significativo, sin embargo, corresponde a líneas de ancho ordinario.

c) Las líneas interiores: Las líneas ferroviarias abandonadas que atraviesan las zonas más internas del país representan en Italia el 67\% del total, lo que corresponde a aproximadamente $5.800 \mathrm{~km}$ de alambres interrumpidos entre montañas y llanuras, entre el norte y el sur. El 47\% de este gran patrimonio abandonado está formado por líneas de ancho ordinario, el 33\% de líneas de vía estrecha, el 13\% de líneas abandonadas como consecuencia de una variante del trazado y el $7 \%$ de líneas inacabadas.

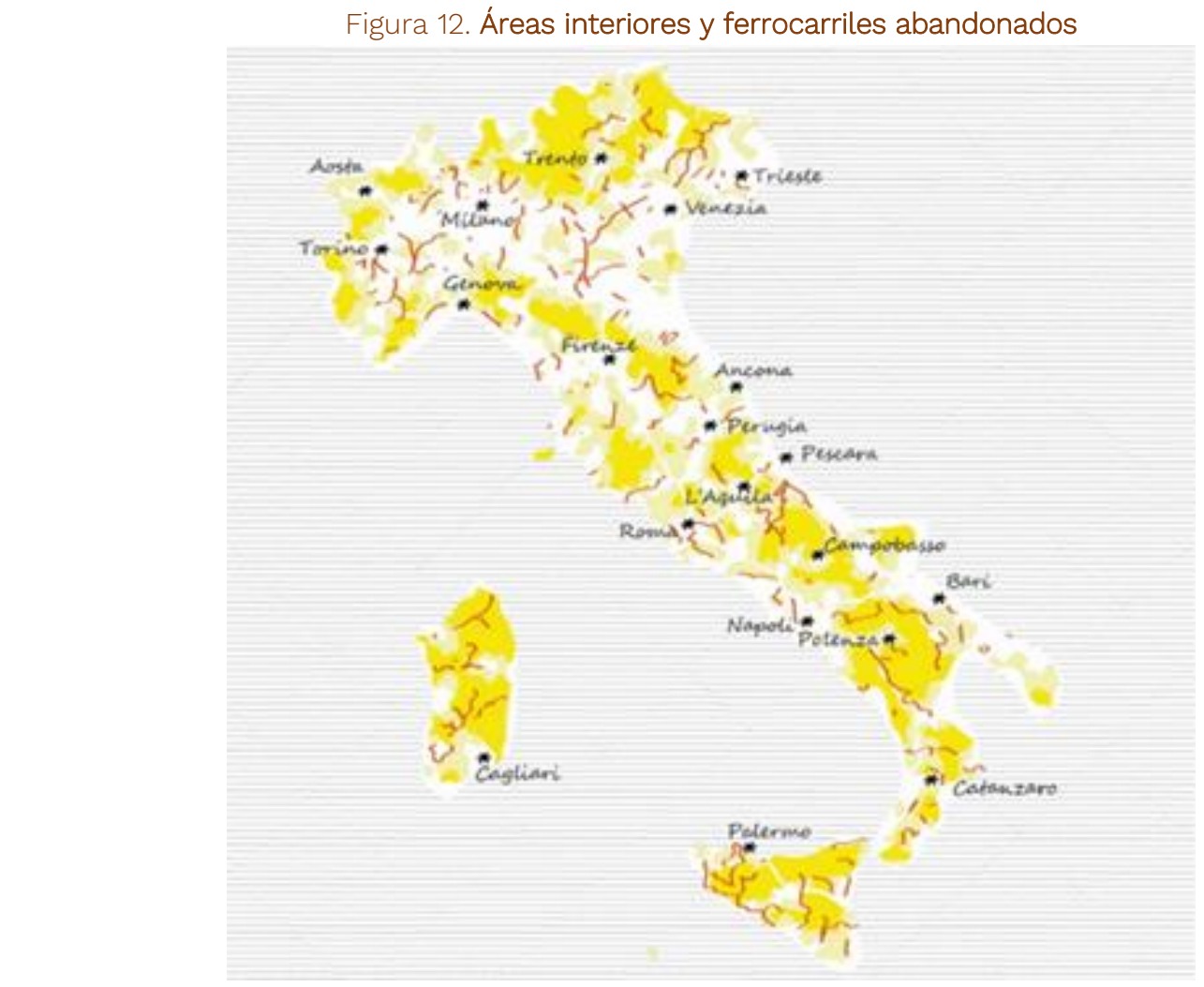

Fuente: Elaboración propia.

ACE, X (XX) CC BY-ND 3.0 ES | UPC Barcelona, España | Rutas de resiliencia en Italia y Espala. Relanzamiento y reutilización de ferrocarriles en territorios frágiles. DOI: http://dx.doi.org/10.5821/ace.15.45.10369 
En este contexto, como se desprende de los casos de estudio abordados en la Investigación, la innovación del urbanismo y la movilidad pasa por la definición de nuevas categorías urbanísticas integradas y multiescalares, orientadas a identificar líneas de intervención en ferrocarriles desmantelados, capaz de transmitir la pluralidad de objetivos (socioeconómicos, culturales, medioambientales) y las relaciones entre ellos (Tabla 2). A partir de las tres perspectivas descritas, la investigación recompone las siguientes categorías de planificación:

a) Corredores multimodales y nodos intermodales, capaces de reducir los tiempos y los costos de viaje e integrar las diferentes formas de movilidad, especialmente en relación con áreas de baja densidad y contextos de asentamiento fragmentado que requieren abordar cuestiones relacionadas con la "movilidad de última milla", ferrocarril-carretera o ferrocarril-bicicleta - para conectar las ciudades más pequeñas con las estaciones de ferrocarril (SNAI);

b) Ferrocarriles turísticos de valor histórico, cultural, arqueológico y paisajístico (Ley 128/2017), capaces de reactivar economías en los centros abandonados por el servicio ordinario, promoviendo actividades culturales, recreativas, artesanales que también sean portadoras de acciones de recuperación patrimonial. asentamiento y ferrocarril (estaciones, túneles, puentes, etc.); $y$,

c) Vías verdes construidas sobre el terreno de vías férreas en desuso, capaces de restaurar la accesibilidad a contextos paisajísticos de gran valor y alta fragilidad ambiental (cascos históricos, costas, valles fluviales, sistema agrícola histórico). Además, estas rutas cumplen con los estándares de rutas, pendientes, secciones e intersecciones limitadas Unión Europea. (2000).

Tabla 2. Líneas de ferrocarriles y rutas territoriales

\begin{tabular}{|l|l|l|l|}
\hline & Líneas de ancho ordinario & Líneas de vías estrechas & Variantes \\
\hline \hline Líneas costeras & \multicolumn{1}{|l|}{\begin{tabular}{l} 
Via Verde del Mar \\
\hline Líneas costa-interior
\end{tabular}} & $\begin{array}{l}\text { Linea Fano-Urbino } \\
\text { Linea Agrigento-Licata }\end{array}$ & $\begin{array}{l}\text { Linea San Vito } \\
\text { Marina - Castel di } \\
\text { Sangro. }\end{array}$ \\
\hline Líneas interiores & $\begin{array}{l}\text { Linea Pau-Canfranc } \\
\text { Linea Sudtirolbahn } \\
\text { Pedemontana del Friuli } \\
\text { Transiberiana d'Italia } \\
\text { Linea Avellino-Rocchetta } \\
\text { Linea Lucca-Aulla }\end{array}$ & Ferrocarril Vasco-Navarro & \\
\hline
\end{tabular}

Fuente: Elaboración propia.

\subsection{Referencias operativas}

Estas líneas de acción sobre ferrocarriles desmantelados deben encontrar espacio en el contexto de una gobernanza multinivel que vincule la planificación física y espacial con enfoques de planificación estratégica, a la luz de escenarios económicos cambiantes, dinámicas de asentamiento y oportunidades de financiamiento articuladas. El planeamiento territorial y urbanístico debe poder contar con procedimientos de co-planificación y cooperación institucional, acompañados de otras herramientas de arriba hacia abajo y de abajo hacia arriba capaces de coordinar acciones en el territorio como resultado de la convergencia de la acción de diversos órganos e instituciones territoriales. involucrados (RFI, Fundación FS, Regiones, Municipios, Ministerios). También es necesario superar un enfoque puramente sectorial de las redes ambientales e infraestructurales, en favor del desarrollo de una dimensión estratégica de la planificación urbano-territorial, paisajística y de movilidad, para definir opciones selectivas vinculadas a políticas de gasto compartido. público para dar sustancia a las operaciones del sistema en las redes (Gasparrini, 2015).

ACE, X (XX) CC BY-ND 3.0 ES | UPC Barcelona, España | Rutas de resiliencia en Italia y Espala. Relanzamiento y reutilización de ferrocarriles en territorios frágiles. DOI: http://dx.doi.org/10.5821/ace.15.45.10369 
En particular, los estudios de caso de investigación destacaron la oportunidad de realizar:

a) Herramientas destinadas a acuerdos multinivel como el Accordo di Programma Quadro y los Protocolli di intesa utilizados para la implementación del SNAI, o inspirados en algunas experiencias francesas relacionadas con el Contrat d'axe;

b) Planificación urbana y herramientas territoriales estructurales-estratégicas de gran extensión con geometría variable capaces de iniciar y consolidar la cooperación intermunicipal y la gestión de servicios asociados, como en el caso de los planes definidos por la Ley de la Región Toscana $\mathrm{n}$. 65/2014; y,

c) Planes de paisaje articulados en una dimensión estratégica basados en la potenciación de redes materiales e inmateriales en el marco de objetivos y acciones compartidos con asociaciones ciudadanas y operadores, integrando las normas para la protección del patrimonio cultural y el paisaje con los proyectos de movilidad, como en el caso del Piano Paesaggistico Territoriale Regionale de la Región Puglia y el Piano paesaggistico de la Región Autónoma Friuli Venezia Giulia (Ravagnan y Amato, 2020).

La definición de objetivos y acciones comunes representa una base sólida para combinar recursos económicos y humanos para la planificación y la gestión. En particular:

- Los Fondos Estructurales, de los cuales el Fondo Europeo Agrario de Desarrollo Rural (Feader) y el Fondo Europeo de Desarrollo Regional (Feder) constituyen los instrumentos más importantes para el desarrollo local integrado y sostenible;

- Financiación nacional (leyes presupuestarias estatales) y regional (PSR);

- Formas de gestión intermunicipal asociada de servicios locales;

- Compensación ambiental en obras de infraestructura;

- Compensación urbano-territorial y ambiental derivada de la planificación;

- Fondos extraordinarios como el Recovery Fund; y,

- Contribuciones de Fundaciones, Asociaciones y sujetos activos en el área.

La Programación 2014-2020 en Italia y la SNAI tuvieron el mérito particular de proponer y promover:

- Una metodología de identificación que considere una pluralidad de factores conectados a los territorios frágiles,

- Líneas de actuación integradas que conectan infraestructuras, movilidad, medio ambiente y territorio;

- Herramientas basadas en formas duraderas de cooperación; y,

- Recursos potenciados por una sinergia de financiación nacional y europea.

Temas que parecen encontrar espacio también en el Plan Next Generation EU que se centra en un transporte y una logística más sostenibles, con apoyo a la movilidad eléctrica, estimulación del transporte ferroviario y movilidad suave. Temas que también son fundamentales para la próxima programación 2021-2027 hacia una Europa más sostenible y conectada.

A la luz de esta evolución cultural, disciplinaria y política y de los análisis presupuestarios que subrayan la posibilidad de inversión por parte de operadores privados (Mattarocci, 2020), así como de las experiencias en curso que destacan la posibilidad de relanzar algunas líneas ferroviarias en disposición a través de la convergencia de recursos (Europea, nacional y autonómica), conviene prestar atención a los vastos activos que se enajenan en el territorio italiano (Rete Ferroviaria Italiana y Ferrovie dello Stato, 2019) y español que claman (desde asociaciones e investigadores) un proyecto compartido por los múltiples niveles institucionales involucrados. Este patrimonio representa no solo una parte significativa de nuestra programación territorial sino también un recurso fundamental para garantizar escenarios de sostenibilidad y cohesión.

ACE, X (XX) CC BY-ND 3.0 ES | UPC Barcelona, España | Rutas de resiliencia en Italia y Espala. Relanzamiento y 23 reutilización de ferrocarriles en territorios frágiles. DOI: http://dx.doi.org/10.5821/ace.15.45.10369 


\section{Autoría}

Este artículo forma parte del trabajo desarrollado por los autores en el marco de la Investigación Rutas de Resiliencia (coordinada por Chiara Ravagnan) a través de una colaboración de las Universidades Sapienza, Roma Tre, Tor Vergata (Italia) y las Universidades de Castilla-La Mancha y Politècnica de Catalunya (España). En este contexto, la introducción ha sido desarrollada, conjuntamente, por la primera autora y el tercer autor. Además, la primera autora ha desarrollado los § 2.1, 2.3 y 4.2; la segunda autora los § 2.2, 3.1 y 4.1; y la tercera autora y el cuarto autor el § 3.2.

Conflicto de intereses: Los autores declaran que no hay conflicto de intereses.

\section{Bibliografía}

Amato, C. (2018). Aree interne e diritto alla mobilità. Nuove opportunità per reti ferroviarie minori e territori fragili. Trabajo presentado en la XXXIX Conferenza Italiana di Scienze Regionali. Recuperado de https://www.aisre.it/2014-07-04-13-37-28/archivio-abstracts\#

Amato, C., Ravagnan, C. y Rossi, F. (2019). Between legacy and abandonment. The reuse of minor railways as resilience paths. En C. Gambardella. (Ed.), World Heritage And Legacy, Culture, Creativity, Contamination, Le Vie dei Mercanti. Atti del XVII International Forum di Studi, Collana Architecture, Heritage and Design (pp 217-226), Roma, Italia: Gangemi. Recuperado de http://cdn.gangemieditore.com/import/materialivari/WORLD\%2OHERITAGE\%20and\%20LEGACY\%20\%20ATTI\%20XVII\%20Forum.pdf

Amato, C., Bevilacqua, G., Ravagnan, C. (2021), The abandoned railway heritage: from problem to opportunity for the regeneration of minor historic centres. En Bevilacqua, C. et al. (eds.), New Metropolitan Perspectives. Knowledge Dynamics and Innovation driven Policies Towards Urban and Regional Transition, 2, 1735-1745. Springer. DOI: https://doi.org/10.1007/978-3-030-48279-4_164

Barca, F., Casavola P. y Lucatelli S. (2014). Strategia Nazionale per le Aree Interne. En Materiali UVAL, 31

Battisti, A. (2020). Resilience of inner areas. Regeneration and enhancement strategies in small towns. Munchen. Germany: Technische Universitat.

Bellet Sanfeliu, C. (2013). Transporte y desarrollo territorial. El estudio de los efectos asociados a la implantación de la alta velocidad ferroviaria a través del caso español. Revista Transporte y Territorio no 8, Universidad de Buenos Aires. Recuperado de www.rtt.filo.uba.ar/rtt00807117.pdf

Blecic, I. y Cecchini, A. (2016). Verso una pianificazione antifragile; come pensare al futuro senza prevederlo. Milano, Italia: Franco Angeli.

Carta, M. y Ronsivalle, D. (2015). Territori interni. La pianificazione integrata per lo sviluppo circolare: metodologie, approcci, applicazioni per i nuovi cicli di vita. Roma, Italia: Aracne.

Cerasoli, M. (2012). Politiche ferroviarie, modelli di mobilità e territorio. Le ferrovie italiane nell'epoca della pseudo liberalizzazione, Roma, Italia: Aracne.

Cerasoli, M. (2015). Qualità urbana, mobilità, qualità della vita: una "grammatica" per il Ri-nascimento della città. Urbanistica Informazioni, 07(263), 16-19.

Cerasoli, M. (2017). La recuperación de los centros históricos menores, hacia las "historical small smart cities". ACE: Architecture, City and Environment, 11(33): 155-180, DOI: http://dx.doi.org/10.5821/ace.11.33.5153

ACE, X (XX) CC BY-ND 3.0 ES | UPC Barcelona, España | Rutas de resiliencia en Italia y Espala. Relanzamiento y reutilización de ferrocarriles en territorios frágiles. DOI: http://dx.doi.org/10.5821/ace.15.45.10369 
Comisión Europea (2013). Green infrastructure strategy. Recuperado de https://ec.europa.eu/environment/nature/ecosystems/index_en.htm

Consejo Europeo (2005). Convenio marco del consejo de Europa sobre el valor del patrimonio cultural para la sociedad, UE. Recuperado de https://rm.coe.int/16806a18d3

Contarino, M. G. y Von Normann, E. (2018). Rileggere un territorio attraverso la ferrovia: il caso dell'rpinia e dell'Avellino - Rocchetta Sant'Antonio, XXXIX Conferenza italiana di scienze regionali Conferenza scientifica annuale AISRe. Resumen recuperado de: https://www.aisre.it/images/aisre/5b8c2b503c6d39.19280986/Contarino\%20Maria\%20Giulia Von\%20 Normann\%20Emanuele.pdf

Del Molino, S. (2016). La España vacía. Viaje por un país que nunca fue. Madrid, España: Turner.

Dematteis, G. (2001). Introduzione. Tema, articolazione e risultati della ricerca. En G. Dematteis y F. Governa. (Eds.), Contesti locali e grandi infrastrutture. Politiche e progetti in Italia e in Europa (pp.1123). Milano, Italia: FrancoAngeli.

De Ureña, J. (Ed). (2012). Territorial Implications of High Speed Rail: A Spanish perspective. Farnham, UK: Ed. Ashgate.

Di Venosa, M. y Morrica, M. (2018). Rigenerare territori fragili. Strategie e progetti. Roma, Italia: Aracne.

ESPON. (2017). PROFECY - Processes, Features and Cycles of Inner Peripheries in Europe. Final Report. Recuperado de https://www.espon.eu/inner-peripheries

ESPON. (2018). Shrinking rural regions in Europe. Towards smart and innovative approaches to regional development challenges in depopulating rural regions. Recuperado de https://www.espon.eu/sites/default/files/attachments/ESPON\%20Policy\%20Brief\%20on\%20Shrinkin g\%20Rural\%20Regions.pdf

Font Arellano A. (Ed). (2007). L'explosión de la ciudad: transformaciones territoriales en las regiones urbanas de la Europa Meridional. Madrid, España: Ministerio de Vivienda.

Gasparrini, C. (2015). In the city on the cities, Trento, Italia: List.

Hirschman, A. (1958). The strategy of economic development. New Haven, Conn. EE.UU.: Yale University Press.

Instituto Nacional de Estadística (2018), Cifras oficiales de población resultantes de la revisión del Padrón municipal a 1 de enero, Recuperado de https://www.ine.es/

Lefebvre, H. (1968). Le Droit à la ville, Paris, France: Anthropos.

Mattarocci, G. (2020). Il potenziale economico delle società ferroviarie che operano nelle aree interne: un’analisi di bilancio. En Ravagnan, C. y Amato, C. Percorsi di resilienza. Rilancio e riuso delle ferrovie in dismissione nei territori fragili tra Italia e Spagna (pp. 359-372). Roma, Italia: Aracne.

Menéndez, J. M., Coronado J. M. y Rivas, A. (2002). El AVE en Ciudad Real y Puertollano. Notas sobre su incidencia en la movilidad y el territorio. Toledo, España: Universidad de Castilla-La Mancha.

Menéndez, J. M., Coronado, J. M. y Rivas, A. (2004). Les effets des navettes TGV sur les villes moyennes: le cas de Ciudad Real et Puertollano en Espagne. Transports urbains, n. 106(1).

ACE, X (XX) CC BY-ND 3.0 ES | UPC Barcelona, España | Rutas de resiliencia en Italia y Espala. Relanzamiento y reutilización de ferrocarriles en territorios frágiles. DOI: http://dx.doi.org/10.5821/ace.15.45.10369 
Naciones Unidas (2005), Millennium Ecosystem Assessment. Recuperado de https://www.millenniumassessment.org/en/index.html

Naciones Unidas (2015). Agenda 2030. Recuperado de https://unric.org/it/agenda-2030/

Palazzo, A. L. (2017). Centri minori e cultura della complessità. Problematiche, prospettive, traiettorie di riuso. ACE: Architecture, City and Environment, 11(33): 213-218. DOI: http://dx.doi.org/10.5821/ace.11.33.5157

Pignatti, L., Rovigatti, P., Angelucci, F. y Villani, M. (2019). (Eds). IFAU '18 - Territori fragili / Fragile territories. Paesaggi_Città_Architetture/ Landscapes_Cities_Architecture. Roma, Italia: Gangemi.

Pike, A., Dawley, S. y Tomaney, Y. (2010). Resilience, adaptation, and adaptability. Cambridge Journal of Regions in Economy and Society, 3(1), 59-70. DOI: https://doi.org/10.1093/cjres/rsq001

Ravagnan, C. (2019). Rigenerare le città e i territori contemporanei. Prospettive e nuovi riferimenti operativi per la sperimentazione, Roma, Italia: Aracne.

Ravagnan, C. y Amato, C. (2020). Percorsi di resilienza. Rilancio e riuso delle ferrovie in dismissione nei territori fragili tra Italia e Spagna. Roma, Italia: Aracne.

Ravagnan C., Cerasoli M., Monardo B. y Valorani C. (2020). Infraestructuras, movilidad y territorio histórico entre shrinkage y regeneración. En Actas de la Conferencia Internacional ISUF 2020, Universidad Politécnica de Cataluña (p. 1-17). Barcelona, Espana: DUOT, UPC. Recuperado de http://hdl.handle.net/2117/328423

Recaño, J. (2017). La sostenibilidad demográfica de la España vacía. En Perspectives demogràfiques, 7, 1-4. Recuperado de https://ced.uab.cat/PD/PerspectivesDemografiques 007 CAST.pdf

Rete Ferroviaria Italiana y Ferrovie dello Stato. (2019). Atlante delle Greenways su linee FS. Dal disuso al riuso. Recuperado de https://issuu.com/ferroviedellostatoitaliane/docs/rfi_atlante_3_green ways_10_12_19_web_d

Ruiz de la Riva, E., Cabana, E., Fernández, P. y Olmo, R. (2015). Territorio y paisaje: notas metodológicas en torno al Plan Especial de Protección de los Valles del Nansa (Cantabria, España). Ciudad y territorio: Estudios territoriales, XLVII(184), 1133-4762. Recuperado de https://recyt.fecyt.es/index.php/CyTET/article/view/76414

Treu, M. y Peraboni, C. (2016) (Eds). Le infrastrutture storiche. Una risorsa per il futuro. Milano, Italia: Maggioli.

Unión Europea. (2000). Lille Declaration. Declaration Towards a "European Greenways Network". Recuperado de https://www.aevv-egwa.org/lille-declaration/ 